JGR Space Physics

\author{
RESEARCH ARTICLE \\ 10.1029/2020JA028216 \\ Special Section: \\ Geospace multi-point observations \\ in Van Allen Probes and Arase era \\ Key Points: \\ - The global distribution of \\ magnetospheric Extremely Low- \\ Frequency/Very Low-Frequency \\ (ELF/VLF) waves was obtained \\ from ground-based and satellite \\ observations, and RAM-SCB \\ simulation \\ - The source region of magnetospheric \\ ELF/VLF wave longitudinally \\ expands in association with \\ substorm injections and eastward \\ electron drift \\ - ELF/VLF waves driven by \\ magnetospheric compression were \\ observed with a longitudinal extent \\ of at least 5 MLT
}

Correspondence to:

K. Shiokawa,

shiokawa@nagoya-u.jp

Citation:

Takeshita, Y., Shiokawa, K., Miyoshi, Y., Ozaki, M., Kasahara, Y., Oyama, S.-i., et al. (2021). Study of spatiotemporal development of global distribution of magnetospheric ELF/VLF waves using ground-based and satellite observations, and RAM-SCB simulations, for the March and November 2017 storms. Journal of Geophysical Research: Space Physics, 126, e2020JA028216. https:// doi.org/10.1029/2020JA028216

Received 9 MAY 2020

Accepted 25 NOV 2020

(C) 2020. American Geophysical Union. All Rights Reserved.

\section{Study of Spatiotemporal Development of Global Distribution of Magnetospheric ELF/VLF Waves Using Ground-Based and Satellite Observations, and RAM-SCB Simulations, for the March and November 2017 Storms}

\author{
Yuhei Takeshita $^{1}$ (D), Kazuo Shiokawa ${ }^{1}$ (D), Yoshizumi Miyoshi ${ }^{1}\left(\mathbb{D}\right.$, Mitsunori Ozaki $^{2}$ (D),

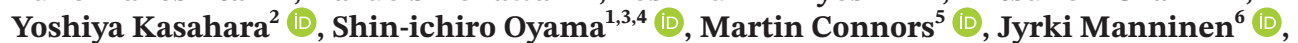 \\ Vania K. Jordanova $^{1,7}$ (D) , Dmitry Baishev ${ }^{8}$ (D), Alexey Oinats ${ }^{9}$, and Vladimir Kurkin ${ }^{9}$ \\ ${ }^{1}$ Institute for Space-Earth Environmental Research, Nagoya University, Japan, ${ }^{2}$ Kanazawa University, Japan, \\ ${ }^{3}$ University of Oulu, Finland, ${ }^{4}$ National Institute of Polar Research, Japan, ${ }^{5}$ Athabasca University, Canada, ${ }^{6}$ Sodankylä \\ Geophysical Observatory, Finland, ${ }^{7}$ Los Alamos National Laboratory, Los Alamos, NM, USA, ${ }^{8}$ Yu.G.Shafer Institute \\ of Cosmophysical Research and Aeronomy of Siberian Branch of the Russian Academy of Sciences, Yakut Scientific \\ Centre of Siberian Branch of the Russian Academy of Sciences, Yakutsk, Russia, ${ }^{9}$ Institute of Solar-Terrestrial Physics, \\ Siberian Branch of the Russian Academy of Sciences, Russia
}

\begin{abstract}
Magnetospheric Extremely Low-Frequency/Very Low-Frequency (ELF/VLF) waves have an important role in the acceleration and loss of energetic electrons in the magnetosphere through waveparticle interaction. It is necessary to understand the spatiotemporal development of magnetospheric ELF/VLF waves to quantitatively estimate this effect of wave-particle interaction, a global process not yet well understood. We investigated spatiotemporal development of magnetospheric ELF/VLF waves using 6 PWING ground-based stations at subauroral latitudes, Exploration of energization and Radiation in Geospace and RBSP satellites, POES/MetOp satellites, and the RAM-SCB model, focusing on the March and November 2017 storms driven by corotating interaction regions in the solar wind. Our results show that the ELF/VLF waves are enhanced over a longitudinal extent from midnight to morning and dayside associated with substorm electron injections. In the main to early storm recovery phase, we observe continuous ELF/VLF waves from $\sim 0$ to $\sim 12$ MLT in the dawn sector. This wide extent seems to be caused by frequent occurrence of substorms. The wave region expands eastward in association with the drift of source electrons injected by substorms from the nightside. We also observed dayside ELF/VLF wave enhancement, possibly driven by magnetospheric compression by solar wind, over an MLT extent of at least $5 \mathrm{~h}$. Ground observations tend not to observe ELF/VLF waves in the post-midnight sector, although other methods clearly show the existence of waves. This is possibly due to Landau damping of the waves, the absence of the plasma density duct structure, and/or enhanced auroral ionization of the ionosphere in the post-midnight sector.
\end{abstract}

Plain Language Summary Extremely Low-Frequency/Very Low-Frequency (ELF/VLF) waves from the Earth's magnetosphere play an important role in the acceleration and loss of energetic electrons in the radiation belts through wave-particle interactions. In order to understand, and possibly to predict, the development and decay of hazardous radiation belt particles, it is necessary to understand spatiotemporal development of magnetospheric ELF/VLF waves. In this paper, we investigated spatiotemporal development of magnetospheric ELF/VLF waves using six ground-based stations, which are longitudinally distributed at subauroral latitudes, three satellites in the inner magnetosphere, several satellites in the ionosphere, and global simulation modeling, focusing on the March and November 2017 geomagnetic storms. Our results show that the ELF/VLF waves are enhanced over a longitudinal extent from midnight to morning and dayside associated with substorm electron injections. In the main to early storm recovery phase, we observe continuous ELF/VLF waves from $\sim 0$ to 12 magnetic local time in the dawn sector. The wave region expands eastward in association with eastward drift of source electrons injected by substorms from the nightside. We also observed dayside wave enhancement, possibly driven by magnetospheric compression by solar wind, over a local time extent of at least $5 \mathrm{~h}$. 


\section{Introduction}

Magnetospheric Extremely Low-Frequency/Very Low-Frequency (ELF/VLF) waves are radio waves with frequency ranges of $0.3-3$ and $3-30 \mathrm{kHz}$ that originate from the magnetosphere. These waves are excited from anisotropic electrons with energies of several to tens of $\mathrm{keV}$ at the equatorial plane of the magnetosphere. The ELF/VLF waves are categorized into several types (e.g. chorus, hiss, and QP) according to their time-frequency spectrum form (e.g., Helliwell, 1965). Chorus waves have a dynamic spectrum composed of discrete emissions, which are characterized mainly as rising-tone structures, but falling-tone structures have also been reported. Chorus waves are often observed as two-banded spectrum in the magnetosphere, i.e., lower-band chorus (LBC) and upper-band chorus (UBC) being respectively below and above half the electron cyclotron frequency ( $1 / 2 \mathrm{f}_{\mathrm{ce}}$ ) (e.g., Anderson \& Maeda, 1977; Omura et al., 2009; Santolik et al., 2003; Tsurutni \& Smith, 1974). Thus, LBC and UBC are often observed with frequencies from $0.1 \mathrm{f}_{\mathrm{ce}}$ up to 0.5 equatorial $\mathrm{f}_{\text {ce }}$ and from 0.5 local $\mathrm{f}_{\mathrm{ce}}$ up to $\mathrm{f}_{\mathrm{ce}}$, respectively. It is known that the LBC can propagate to the low altitudes and to the ground (e.g., Smith et al., 1960) either by gradual refraction of waves generated at oblique wave vectors in a smooth magnetosphere (e.g., Santolik et al., 2006) or by propagation in plasma density ducts (e.g., Streltsov et al., 2006; Hanzelka \& Santolik, 2019).

In recent studies, it is revealed that magnetospheric ELF/VLF waves contribute to the plasma dynamics in the magnetosphere through wave-particle interactions. Chorus waves and energetic electrons traveling in the opposite direction can interact with each other when the Doppler-shifted wave frequency and electron cyclotron frequency are the same. As a result, energy can be transported from electrons to waves or from waves to electrons, i.e., cross-energy coupling takes place between plasma/particle distributions (e.g., Miyoshi et al., 2015a). Some energetic electrons are scattered by magnetospheric ELF/VLF waves into smaller pitch angles, and then precipitate into the upper atmosphere and are lost from the magnetosphere (e.g., Jordanova et al., 2016; Ozaki et al., 2018a; Ozaki et al., 2019). The energy of electrons scattered by ELF/ VLF waves depends on the magnetic latitude at which the resonance occurs, and these waves can scatter tens of keV electrons at near the equator and relativistic electrons at high latitudes (Horne \& Thorne, 2003, Miyoshi et al., 2015a, 2015b). On the other hand, it is also known that magnetospheric ELF/VLF waves can accelerate electrons and then generate relativistic electrons in the radiation belts (e.g., Summers et al., 1998, 2002; Miyoshi et al., 2003, 2013; Meredith et al., 2003a).

The magnetospheric ELF/VLF wave distribution has been investigated to estimate the effect of magnetospheric ELF/VLF waves on energetic electron loss and generation. Using Combined Release and Radiation Effects Satellite (CRRES) and Time History of Events and Macroscale Interactions during Substorms (THEMIS) satellites, Meredith et al. (2003b, 2012) and Li et al. (2009), respectively, investigated the distribution of magnetospheric ELF/VLF wave amplitude statistically as a function of MLT and $L$-value. Martinez-Calderon et al. (2015) have shown local time variation of magnetospheric ELF/VLF waves based on one-year observation at one station in Canada at subauroral latitudes. Takeshita et al. (2019) investigated instantaneous longitudinal extent of magnetospheric ELF/VLF waves using 6 multipoint ground stations, and estimated a typical wave extent to be $\sim 76^{\circ}$ in longitude. They used ground-based stations constructed by the PWING (study of dynamical variation of Particles and Waves in the INner magnetosphere using Groundbased network observations) Project (Shiokawa et al., 2017). These studies are useful for understanding average distribution of wave generation region. However, since the magnetospheric ELF/VLF waves resonate with electrons which are dynamically varying and drifting eastward in the magnetosphere, it is important to know the spatiotemporal development of ELF/VLF waves in the magnetosphere. The spatiotemporal development of ELF/VLF waves during magnetic storms has not well been understood.

In this study, we investigate the spatiotemporal development of the global distribution of ELF/VLF waves for the first time, focusing on March and November 2017 storms. Both storms were driven by corotating interaction region (CIR) in the solar wind and subsequent coronal hole streams. Typical variations of the inner magnetosphere associated with the high-speed streams (e.g., Miyoshi et al., 2013, 2016) are seen in the plasmasphere, hot electrons, chorus waves, and radiation belts. Several evidences of chorus-wave particle interactions have been reported by the Exploration of energization and Radiation in Geospace (ERG, also called Arase) satellite (e.g., Kurita et al., 2018, Kasahara et al., 2018a; Ozaki et al., 2018a; Hosokawa et al., 2020). In this study, we use multiple observations and simulation data: (1) PWING ground-based simultaneous observations (e.g., Shiokawa et al., 2014; Yonezu et al., 2017; Takeshita et al., 2019); (2) simultaneous 


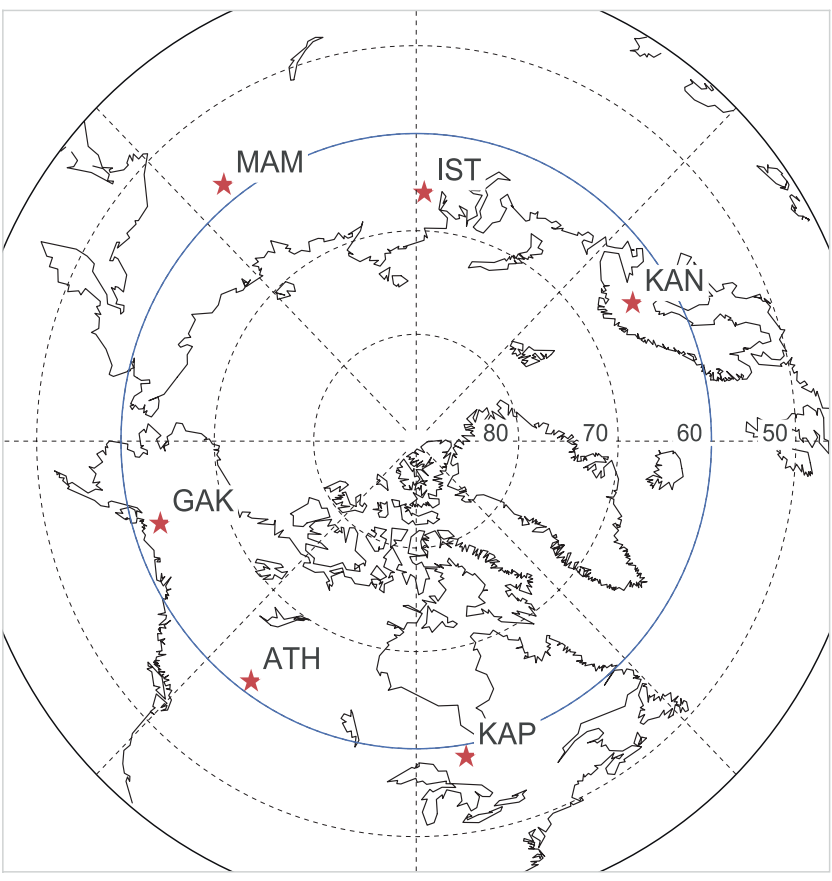

Figure 1. The MLAT and MLT map of PWING stations. observations by the ERG (Miyoshi et al., 2015a) and Radiation Belt Storm Probes (RBSP, also called as Van Allen Probes) satellites (Mauk et al., 2013); (3) scattered electron observations by the NOAA Polar Operational Environment Satellites (POES) and European Organization for the Exploitation of Meteorological Satellites (EUMETSAT) MetOp satellites (e.g., Li et al., 2013; Chen et al., 2014); and (4) linear growth rate of chorus wave calculated by the Ring current Atmosphere interactions Model with Self Consistent magnetic field (RAM-SCB) simulations (e.g., Jordanova et al., 2010; 2012).

\section{Data Analysis}

\subsection{Ground-Based PWING Observations}

As shown in Figure 1, the PWING ground-based stations used in the present analysis are located at Kapuskasing (KAP; maglat: $58.7^{\circ} \mathrm{N}$, maglon: $354.0^{\circ} \mathrm{E}$ ) and Athabasca (ATH; maglat: $61.3^{\circ} \mathrm{N}$, maglon: $309.0^{\circ} \mathrm{E}$ ) in Canada, Gakona (GAK; maglat: $63.0^{\circ} \mathrm{N}$, maglon: $271.8^{\circ} \mathrm{E}$ ) in USA, Maimaga (MAM; maglat: $58.0^{\circ} \mathrm{N}$, maglon: $202.6^{\circ} \mathrm{E}$ ) and Istok (IST; maglat: $66.1^{\circ} \mathrm{N}$, maglon: $162.7^{\circ} \mathrm{E}$ ) in Russia, and Kannuslehto (KAN; maglat $64.5^{\circ} \mathrm{N}$; maglon: $\left.106.0^{\circ} \mathrm{E}\right)$ in Finland. These stations are located at an $L$-value range from 3.5 to 6.5 (calculated by the IGRF-12 model (Thebault et al., 2015)) and distributed around the North Pole. These stations have the same type of loop antennas (Ozaki et al., 2008) with a 10-loop delta-type antenna and a sampling frequency of $40 \mathrm{kHz}$ to observe ELF/VLF waves except for KAN (10-loop mast-type antennas, sampling frequency: $78.125 \mathrm{kHz}$ ). During the March 2017 storm, the GAK, MAM, and IST were not in operation, thus we use data from ATH, KAP, and KAN. During the November 2017 storm, we use data from all six stations.

Figure 2 shows the dynamic spectra of ELF/VLF waves observed on November 21, 2017 at these stations. The red arrows indicate local midnight. Power-line/broadcast noise and sferics from the lightning were removed from these spectra using a signal processing technique (Manninen et al., 2016). We can see long lasting ( 4 h) ELF/VLF waves at frequencies of 1-5 kHz at 7-10 UT and 15-19 UT at ATH, 16-20 UT at GAK, 20-24 UT at MAM, 1-4 UT at IST, and 4-9 UT at KAN, as indicated by red horizontal bars at the top of these panels. Other structures seen in these spectra are probably from sferics which could not be removed by the sferics filtering.

To compare these wave activities with other data, we defined the period of wave existence every 1 min through visual inspection of dynamic spectra. We also defined the power of ELF/VLF waves from the wave power at frequencies from 2 to $4 \mathrm{kHz}$. These wave powers are divided by quiet-day curves of the wave power per each station. This is to normalize the difference of wave power at different ground stations due to different gain and sferics filter (for KAN). The quiet day curve was obtained by fitting a sinusoidal function with a period of one day to the wave-power data obtained at one day before the storm (March 26, 2017 and November 19, 2017). Figure 3 shows the quiet-day curves of November 19, 2017 for the 6 stations with fitting of a sinusoidal curve (yellow line) with a period of $24 \mathrm{~h}$. The wave power shows daily variations which basically follow this 24-h sinusoidal function, because the variation of sferics noise follows the local time variations of lightning sources at equatorial latitudes. Sometimes the signal goes significantly below this quiet-day curve, because sferics intensity varies due to local weather condition at equatorial latitudes.

\subsection{ERG and RBSP Satellite Observations}

The ERG and RBSP satellites are used for exploration of the ELF/VLF waves in the inner magnetosphere. They are operated in elliptical orbits with perigees of $\sim 440 \mathrm{~km}$ and $\sim 620 \mathrm{~km}$ and apogees of $\sim 32,000 \mathrm{~km}$ and 30,500 km, respectively (Miyoshi et al., 2015a; Mauk et al., 2013). During the March 2017 storm, the 


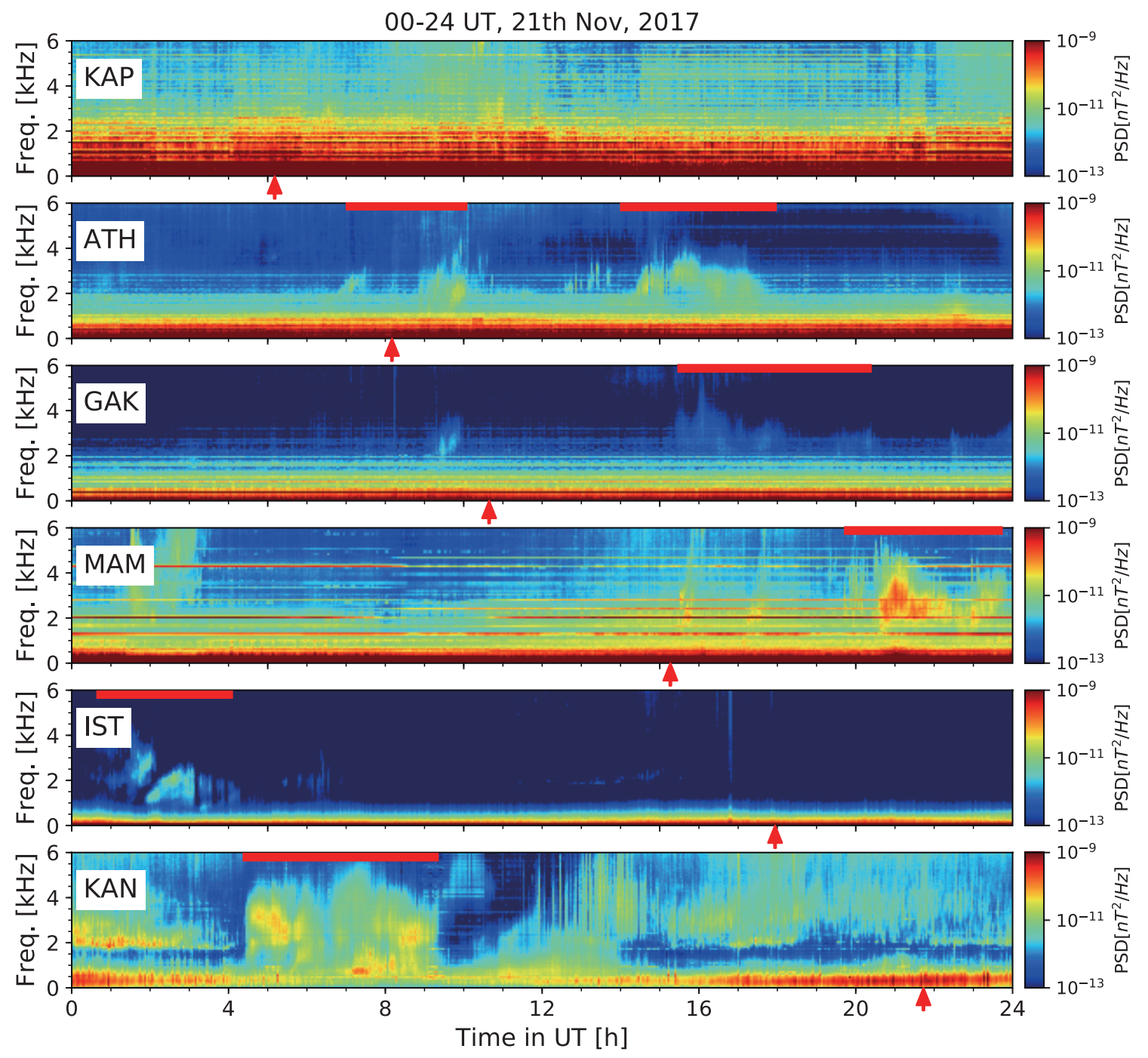

Figure 2. One-day dynamic spectra of ELF/VLF waves observed by ground PWING stations (KAP: Kapuskasing, ATH: Athabasca, GAK: Gakona, MAM: Maimaga, IST: Istok, KAN: Kannuslehto) on November 21, 2017. These spectra had noise removed using signal processing. The red arrows in these panels indicate the local midnight. ELF/VLF, Extremely Low-Frequency/Very Low-Frequency.

apogees of ERG and RBSP were located post-midnight ( 3 MLT) and dusk ( 19 MLT) sectors, respectively, and their orbits were located near the equatorial plane of the magnetosphere, as shown in Figures $4 \mathrm{a}$ and $4 \mathrm{~b}$. The orbits near the equatorial plane were suitable for measurement of the chorus waves near the generation region. In contrast, during the November 2017 storm, the apogees of ERG and RBSP were located in the dusk ( 17 MLT) and pre-noon ( 10 MLT) sectors, respectively, and the ERG orbits were located at high latitudes, as shown in Figures $4 \mathrm{c}$ and $4 \mathrm{~d}$. This orbital configuration was suitable for measurement of the chorus waves that propagate to high latitudes.

For the ERG satellite, the Onboard Frequency Analyzer (OFA) of the Plasma Wave Experiment (PWE; Kasahara et al., 2018a) provides dynamic power spectra of magnetic field component of plasma waves observed by the Magnetic Search Coil (MSC; Ozaki et al., 2018b). For the RBSP satellite, the Electric and Magnetic Field Instrument Suite and Integrated Science (EMFISIS; Kletzing et al., 2013) provides wave measurement data. The Waveform Receiver (WFR), which is a component of EMFISIS, provides dynamic power spectral density of magnetic field measured by the triaxial AC magnetic search coil magnetometer (MSC).

Figures $5 \mathrm{a}-5 \mathrm{c}$ show the 1-day dynamic spectrum of total wave power in the magnetic field observed by RBSP-A, RBSP-B, and ERG, respectively, on November 21, 2017. The white lines in these spectra indicate 1, 1/2, 
(a)

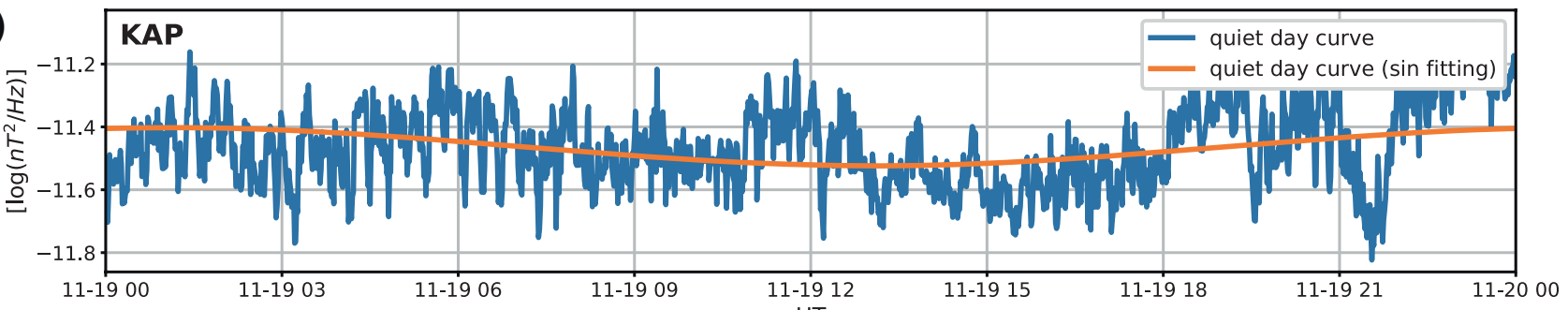

(b)

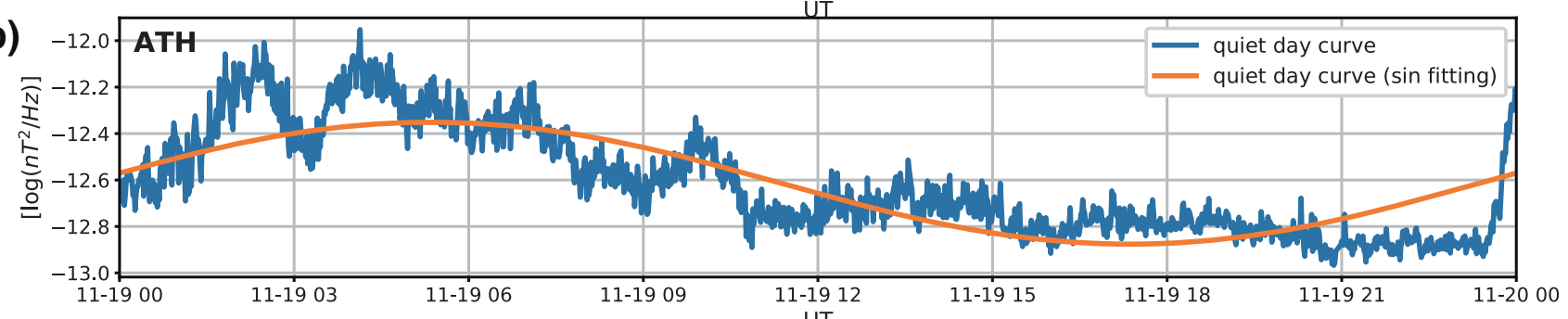

(c)

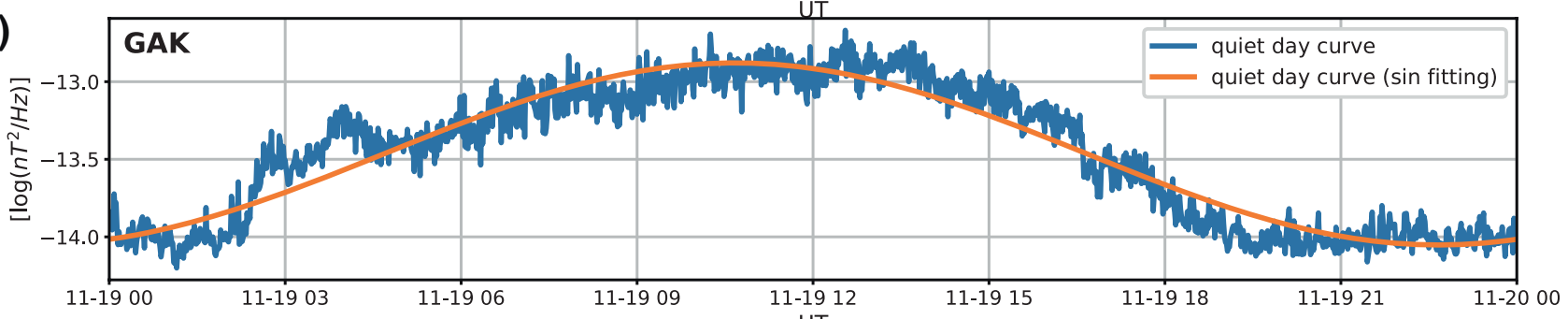

(d)

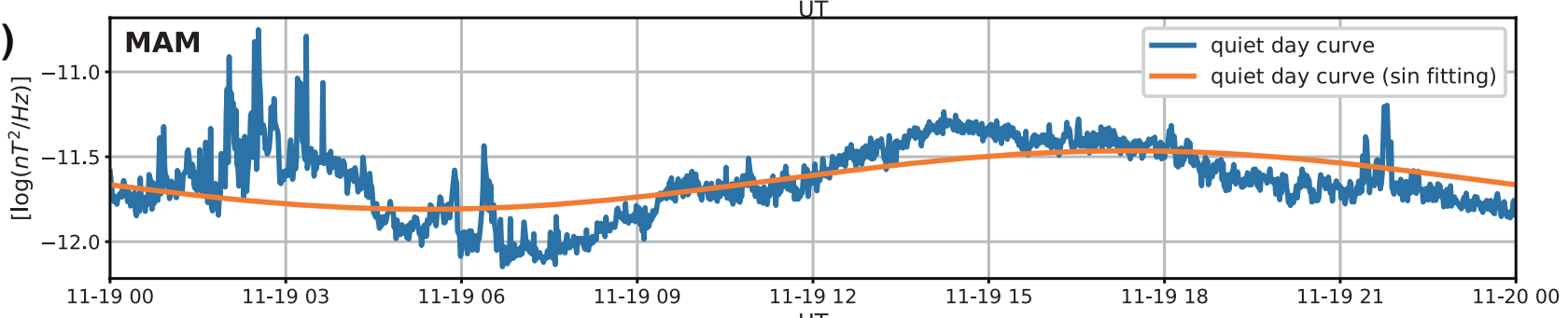

(e)

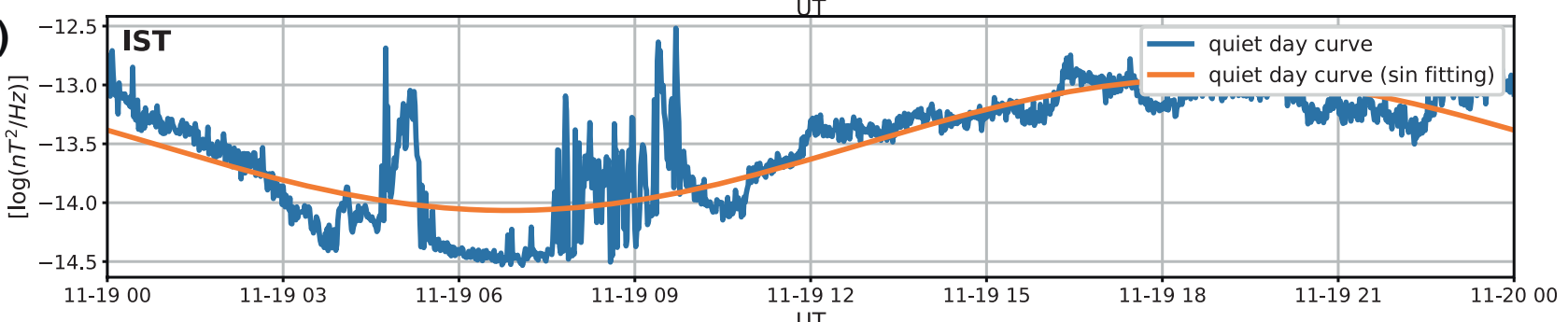

(f)

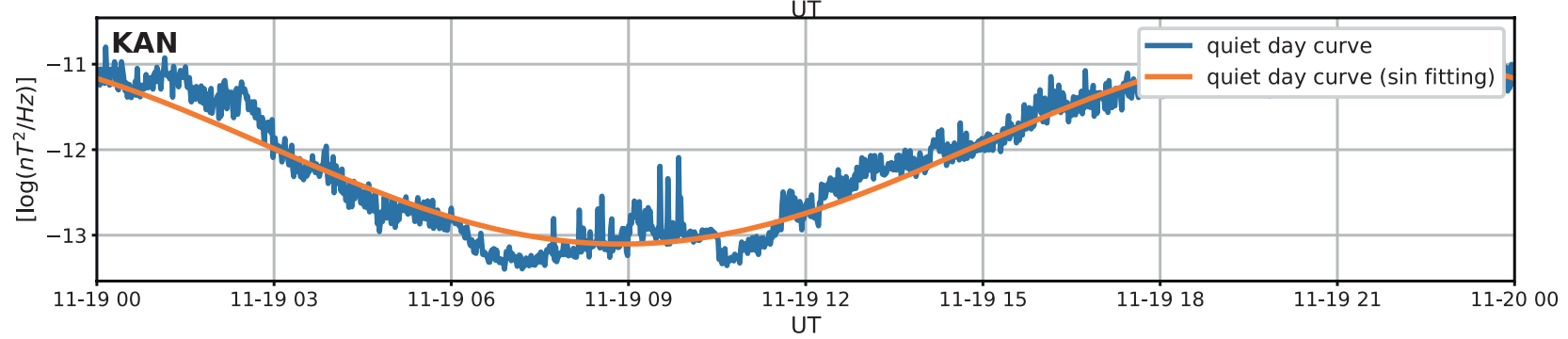

Figure 3. ELV/VLF wave intensities at frequencies from 2 to $4 \mathrm{kHz}$ on November 19, 2017 before the storm. The yellow lines indicate sinusoidal fits which are used as the quiet-day curves. ELF/VLF, Extremely Low-Frequency/Very Low-Frequency. 


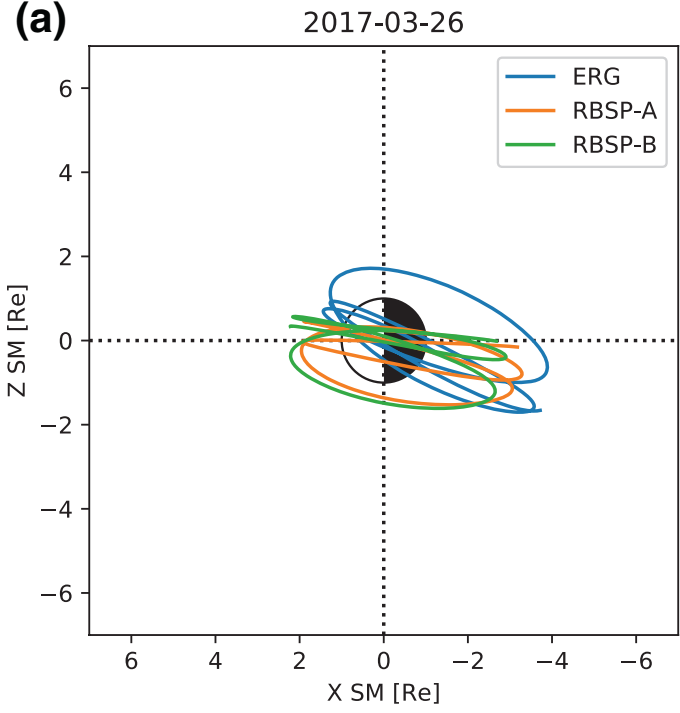

(c)

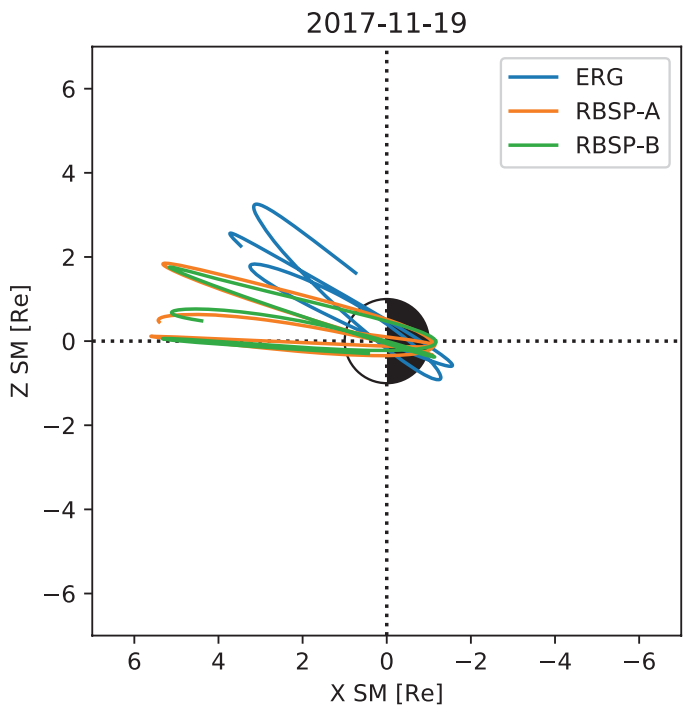

(b)

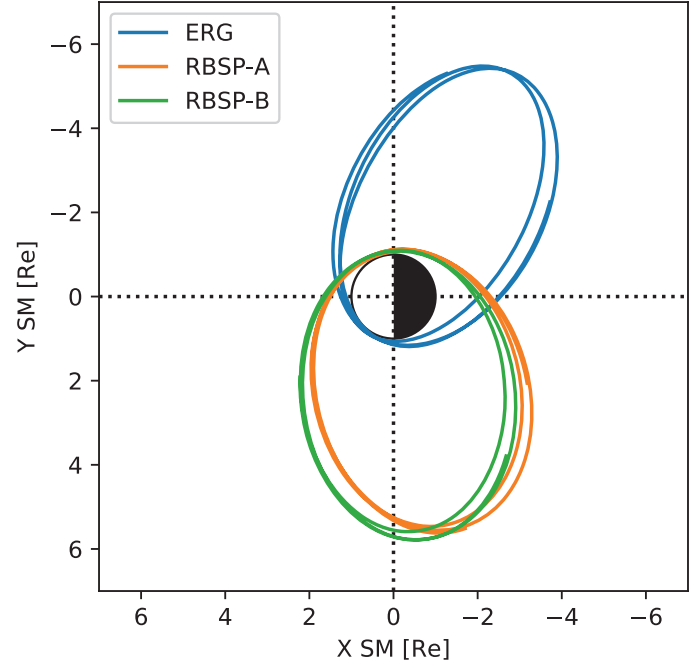

(d)

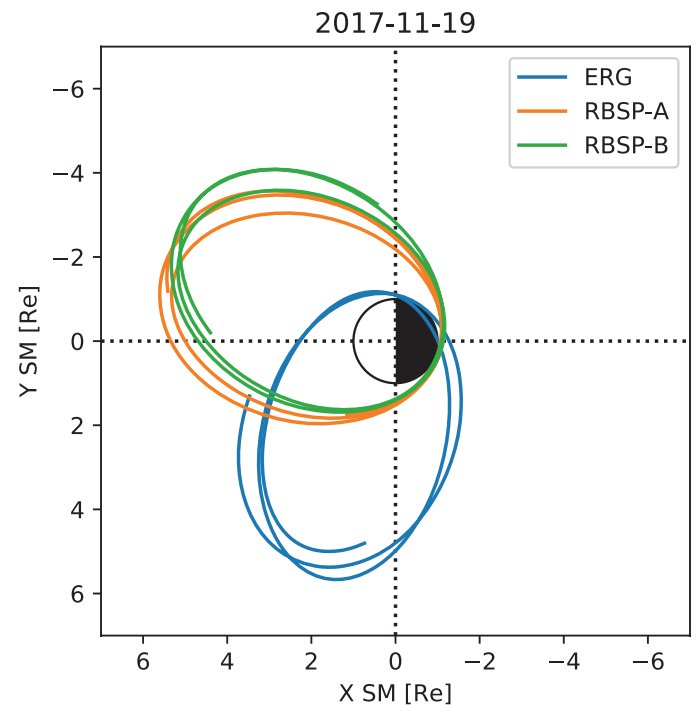

Figure 4. Orbits of ERG and RBSP satellites on March 26, 2017 (a and b) and on November 19, 2017 (c and (d) in the SM coordinates. ERG, Exploration of energization and Radiation in Geospace; SM, Solar Magnetospheric.

1/10 electron cyclotron frequencies $\left(f_{\text {ce }}\right)$ at the equatorial plane of the magnetosphere calculated by the Tsyganenko-04 (T04) model with parameters of solar wind dynamic pressure, Dst, IMF-By and -Bz, and others (Tsyganenko and Sitnov., 2005). Magnetospheric ELF/VLF waves are observed at frequencies between $0.1 \mathrm{f}_{\mathrm{ce}}$ and $1.0 \mathrm{f}_{\mathrm{ce}}$ for most of the plotted intervals by the RBSP satellites in Figures $5 \mathrm{a}$ and $5 \mathrm{~b}$ in the dawn-pre-noon sector, while such waves were not observed by ERG in Figure 5c in the dusk sector. Low-frequency waves below $0.1 f_{\text {ce }}$ observed near the perigee are whistler-mode waves which are out of interest in the present study. ERG often observed electrostatic-like chorus emission that does not have a significant magnetic field component. These electrostatic waves were not included in this analysis.

In order to investigate the time dependent global distribution of magnetospheric ELF/VLF waves, we binned these spectra every $0.25 \mathrm{Re}(\mathrm{L}) \times 0.5 \mathrm{~h}(\mathrm{MLT}) \times 10 \mathrm{~min}(\mathrm{UT})$, for which L value and MLT are obtained by mapping the orbit of the satellites to the equatorial plane using the T04 model (Tsyganenko \& Sitnov, 2005). Then we calculated magnetic field amplitude of lower-band ELF/VLF waves by integrating power spectra over the lower-band frequency range (0.1-0.5 $\mathrm{f}_{\mathrm{ce}}$ ) (Santolik et al., 2005). Figure 6a shows the global distribution of the obtained wave amplitudes of the ELF/VLF waves for $8 \mathrm{~h}$ of 03-11 UT on November 21, 2017. 
(a) $\quad$ ERG PWE OFA L2 SPEC B 2017-11-21

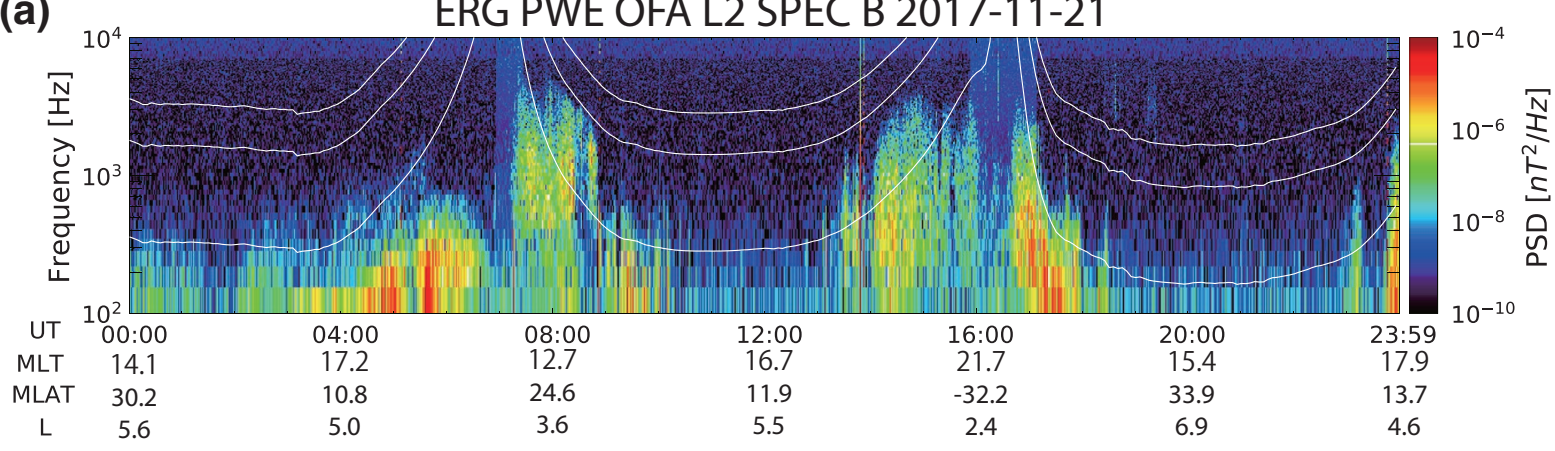

(b) RBSP-A WFR SPECTRAL MATRIX EMFISIS-L2 2017-11-21

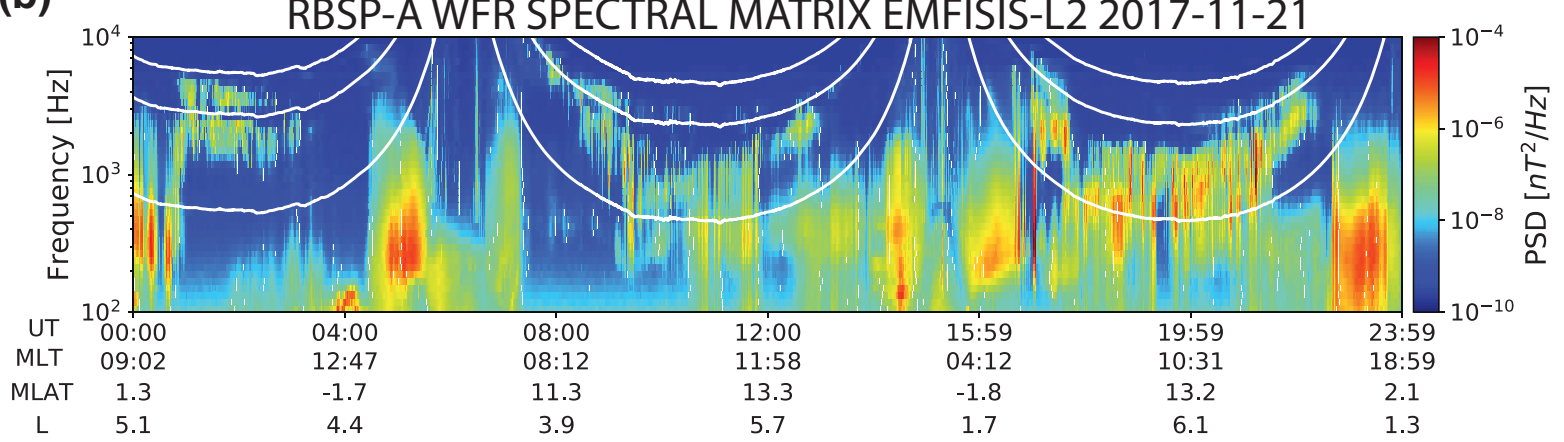

(c)

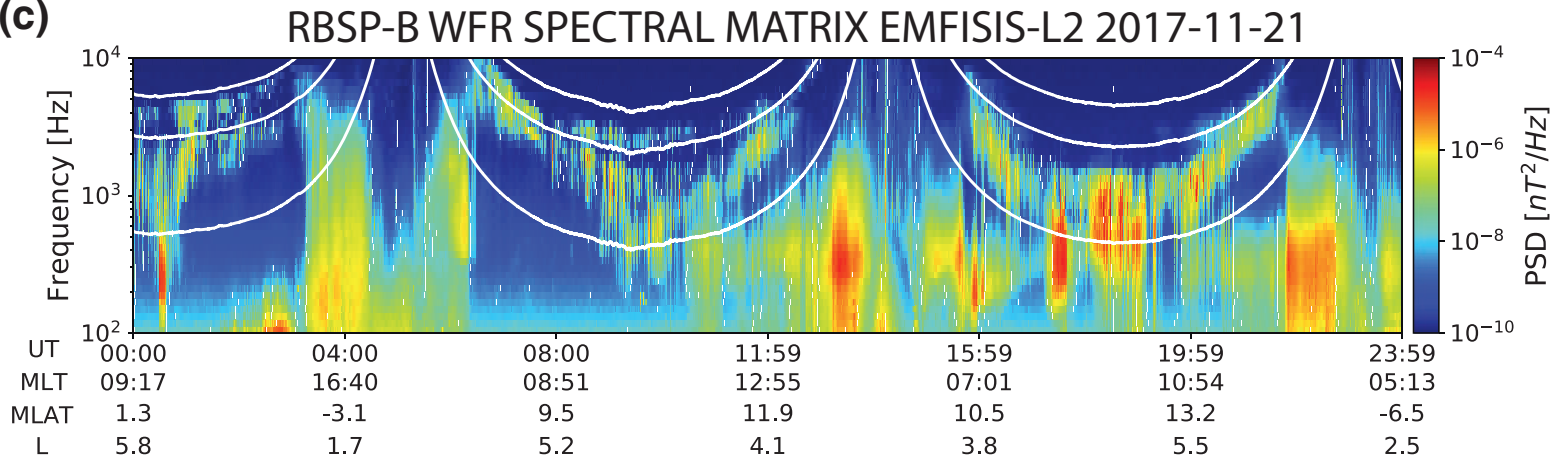

Figure 5. One-day dynamic spectra of ELF/VLF waves observed by (a) ERG satellite, (b) RBSP-A satellite, and (c) RBSP-B satellite on November $21,2017$. The white lines indicate, from top to bottom, 1, 0.5, and 0.1 times the electron gyro frequencies at the equatorial plane derived from the T04 model. ELF/VLF, Extremely Low-Frequency/Very Low-Frequency; ERG, Exploration of energization and Radiation in Geospace.

\subsection{POES/MetOp Satellite Observations}

POES and MetOp satellites are polar orbiting satellite series which consist of several satellites with an altitude of $\sim 800 \mathrm{~km}$ and an orbital period of $\sim 100 \mathrm{~min}$. The Space Environment Monitor (SEM-2; (Evans \& Greer., 2004) on board POES/MetOp provides measurement of the electron flux with energies from $30 \mathrm{keV}$ to $2.5 \mathrm{MeV}$ observed by the Medium Energy Proton and Electron Detector (MEPED; e.g, Miyoshi et al., 2013). The energy ranges of the three electron channels are $30-2,500 \mathrm{keV}, 100-2,500 \mathrm{keV}$, and 300-2,500 keV. The MEPED have two telescopes of $0^{\circ}$ and $90^{\circ}$ with $30^{\circ}$ field of view. The $0^{\circ}$ telescope and the $90^{\circ}$ telescope can measure mainly the precipitating and trapped particles, respectively, at the subauroral and auroral zones.

Li et al. (2013) and Chen et al. (2014) proposed a method to estimate amplitude of magnetospheric chorus waves from the precipitating electrons measured by the MEPED. In this study, we estimate wave amplitude using the empirical model by Chen et al. (2014) for $>30 \mathrm{keV}$ electron flux observed by the $0^{\text {[? }}$ telescope. The estimated amplitude of waves was binned every $0.25 \mathrm{Re}(\mathrm{L}) \times 0.5 \mathrm{~h}(\mathrm{MLT}) \times 30 \mathrm{~min}(\mathrm{UT})$. Figure $6 \mathrm{~b}$ shows the global distribution of the estimated amplitudes of magnetospheric chorus waves obtained for 06-08 UT on November 21, 2017. 

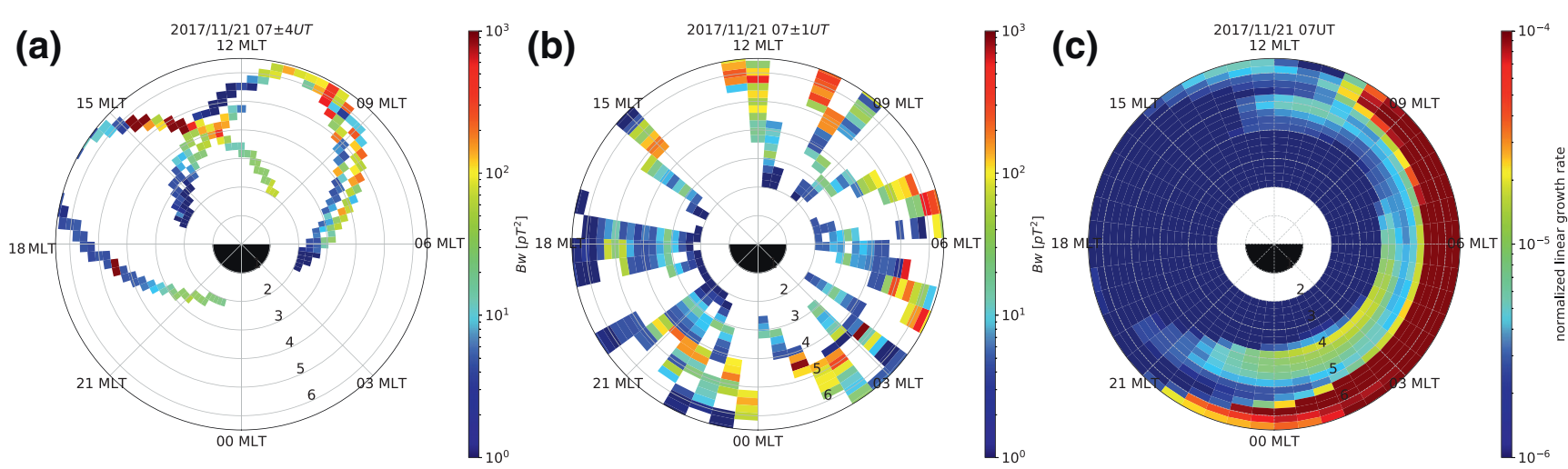

Figure 6. Spatial distribution of (a) magnetospheric ELF/VLF wave amplitude observed by the ERG and RBSP satellites for 8-h, (b) magnetospheric ELF/VLF wave amplitude estimated from scattered precipitating electrons observed by the POES/MetOp satellites for $2 \mathrm{~h}$, and (c) linear growth rate of ELF/VLF waves calculated from the RAM-SCB simulation for $1 \mathrm{~h}$, centered at 07 UT on November 21, 2017. ELF/VLF, Extremely Low-Frequency/Very Low-Frequency; ERG, Exploration of energization and Radiation in Geospace.

\subsection{RAM-SCB Simulations}

The RAM-SCB model solves the bounce-averaged kinetic equation for electrons and $\mathrm{H}^{+}, \mathrm{O}^{+}$, and $\mathrm{He}^{+}$ions, using a magnetic field calculated with the two-way coupled 3D Euler-potential-based equilibrium code (e.g., Jordanova et al., 2010; 2012). It calculates the distribution function of electrons and $\mathrm{H}^{+}, \mathrm{O}^{+}$, and $\mathrm{He}^{+}$ions in the equatorial plane as a function of magnetic local times (MLTs) in steps of $1 \mathrm{~h}$, radial distances R from 2 to $6.5 \mathrm{R}_{\mathrm{E}}$ in steps of $0.25 \mathrm{R}_{\mathrm{E}}$, kinetic energies from $100 \mathrm{eV}$ to $400 \mathrm{keV}$, and pitch angles from $0^{\circ}$ to $90^{\circ}$. It uses plasma sheet flux measured from the Magnetospheric Plasma Analyzer (MPA) and the Synchronous Orbit Particle Analyzer (SOPA) on the Los Alamos National Laboratory (LANL) spacecraft, as a boundary condition.

The temporal linear growth rate of whistler mode waves was calculated using the dispersion relation of whistler mode waves. Specifically, we have used the temperature anisotropy, hot electron density, and ambient magnetic field and density, provided from the RAM-SCB model for the linear growth rate calculation using the analytical expressions of Kennel and Petschek (1966). We used this linear growth rate as a proxy of the wave generation. The linear growth rate was normalized by electron cyclotron frequency $\left(\mathrm{f}_{\mathrm{ce}}\right)$ in the equator plane.

In the RAM-SCB model, the normalized linear growth rates of chorus wave were binned every $0.25 \mathrm{R}_{\mathrm{E}}(\mathrm{L})$ $\times 0.5 \mathrm{~h}(\mathrm{MLT}) \times 0.01 \mathrm{f}_{\mathrm{ce}} \times 1 \mathrm{~h}$ in UT. In this study, we used the maximum linear growth rate within the lower-band frequency range $\left(0-0.5 \mathrm{f}_{\mathrm{ce}}\right)$ and we do not consider the convective growth rate. Figure $6 \mathrm{c}$ shows the global distribution of normalized linear growth rate on 07 UT, 21 November 2017 calculated by the RAM-SCB simulation.

We should note that the chorus generation process contains linear and nonlinear growth, which are both important. The nonlinear growth is important because whistler-mode waves ultimately grow nonlinearly to a saturation level (Omura \& Summers, 2004). Investigating non-linear growth rate and convective growth rate (e.g., Horne, 1989) with ray-tracing, however, requires high-performance computing power and cannot be applied to the global and storm-time scale simulations. The linear growth is important because it provides the initial amplification that raises the weak signals to levels at which nonlinear trapping of electrons takes place [Nunn et al., 2003] and is suitable for implementation in large-scale models (Jordanova et al., 2010) to investigate the chorus dynamics on a global scale as is the main objective of this paper.

\section{Comparison of Observations and the RAM-SCB Modeling}

To investigate spatiotemporal distribution of magnetospheric ELF/VLF waves, we investigated time-MLT development of the waves measured by the PWING ground stations and the ERG and RBSP satellites and estimated from POES/MetOp electron fluxes, and the development of the linear growth rate of chorus waves calculated by the RAM-SCB model. For the comparison, we used two storm events in March and November 2017. 
(a)

(b)

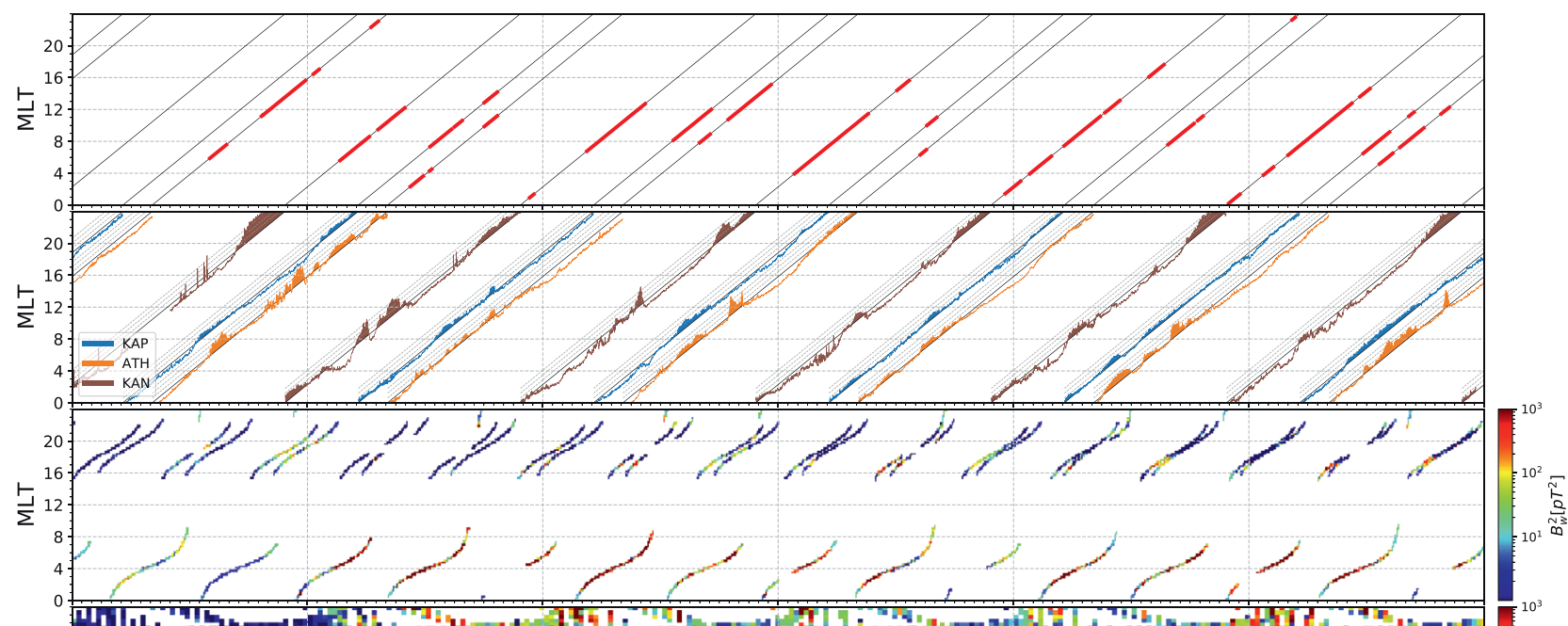

(d)

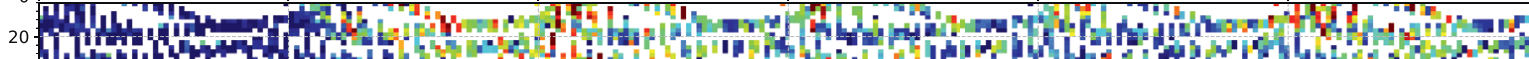

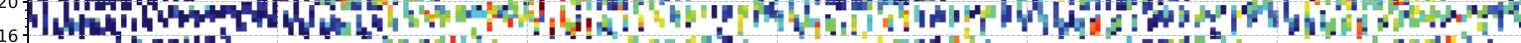
$\vdash$ |

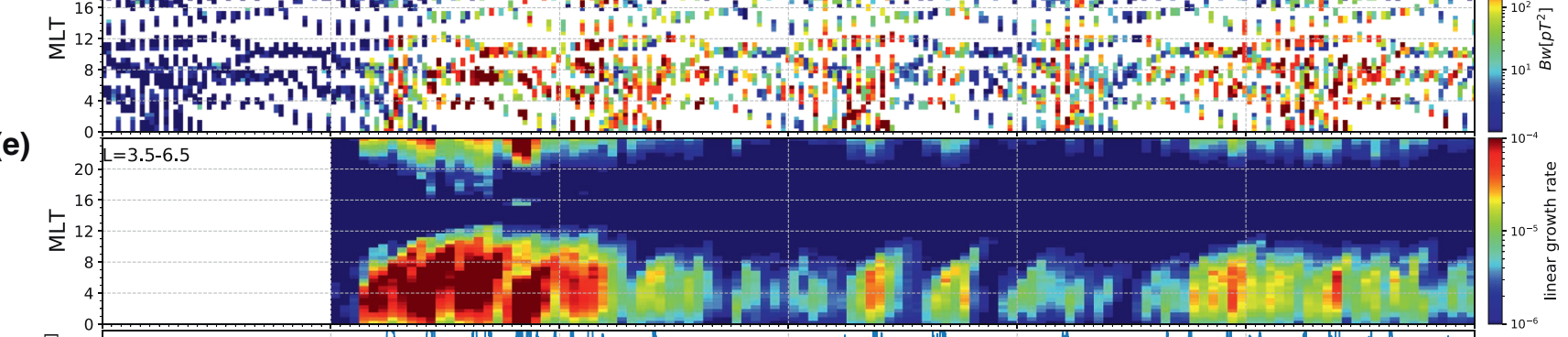

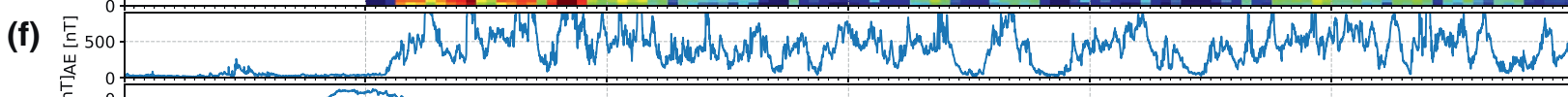

(g) $\frac{5}{5}-50$ c

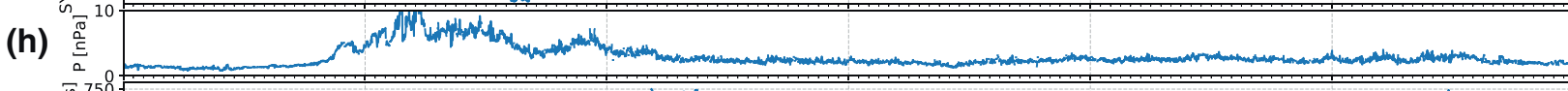

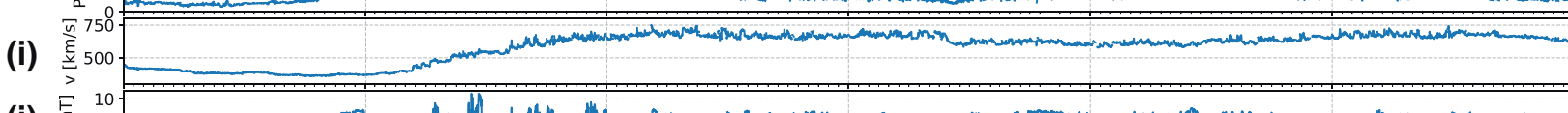

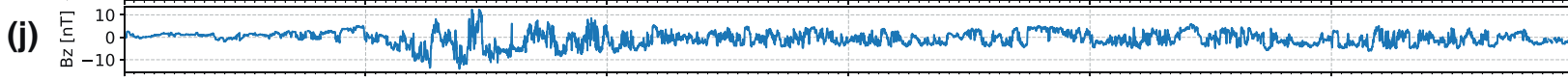
$\begin{array}{llllllllll}2017-03-26 & 2017-03-27 & 2017-03-28 & 2017-03-29 & 2017-03-30 & 2017-03-31 & \end{array}$

Figure 7. Spatiotemporal distribution of magnetospheric ELF/VLF waves for the storm from March 26, 2017 to April 1, 2017, observed by (a) and (b) PWING, (c) ERG and RBSP satellites, and (d) POES/MetOp and estimated by (e) RAM-SCB simulation. Panels (f), (g), (h), (i), and (j) show the time variation of AE index, SYM-H index, solar wind dynamic plessure, solar wind speed and IMF-Bz, respectively. AE, Auroral Electrojet; ELF/VLF, Extremely Low-Frequency/ Very Low-Frequency; ERG, Exploration of energization and Radiation in Geospace.

The top panels of Figures 7-9 are time-MLT plots of wave existence periods observed by the PWING stations (described in Section 2.1). The dashed black line indicates MLT locations of the PWING stations for each time. The thick red lines indicate wave existence period defined by visual inspection. The second panels of Figures 7-9 show time-MLT plot of wave power within a frequency range from 2 to $4 \mathrm{kHz}$ (described in Section 2.1). The colored line indicates the median wave power taken every 1 min for a frequency range from $2 \mathrm{kHz}$ to $4 \mathrm{kHz}$ and is plotted on MLT of PWING stations. The black solid line indicates the baseline (quiet-day curve of wave power) and the separation of dashed lines indicate one order. For example, the signal that reaches the third line has the wave power 1,000 times higher than the quiet-day curve. The period when the wave power exceeds the baseline indicates excitation of the waves.

The third, fourth, and fifth panels of Figures 7-9 are time-MLT plots of wave amplitudes measured by ERG and RBSP (described in Section 2.2), wave amplitudes estimated from POES/MetOp electron fluxes (described in Section 2.3), and linear growth rate of chorus waves calculated by the RAM-SCB code 
(a)

(b)

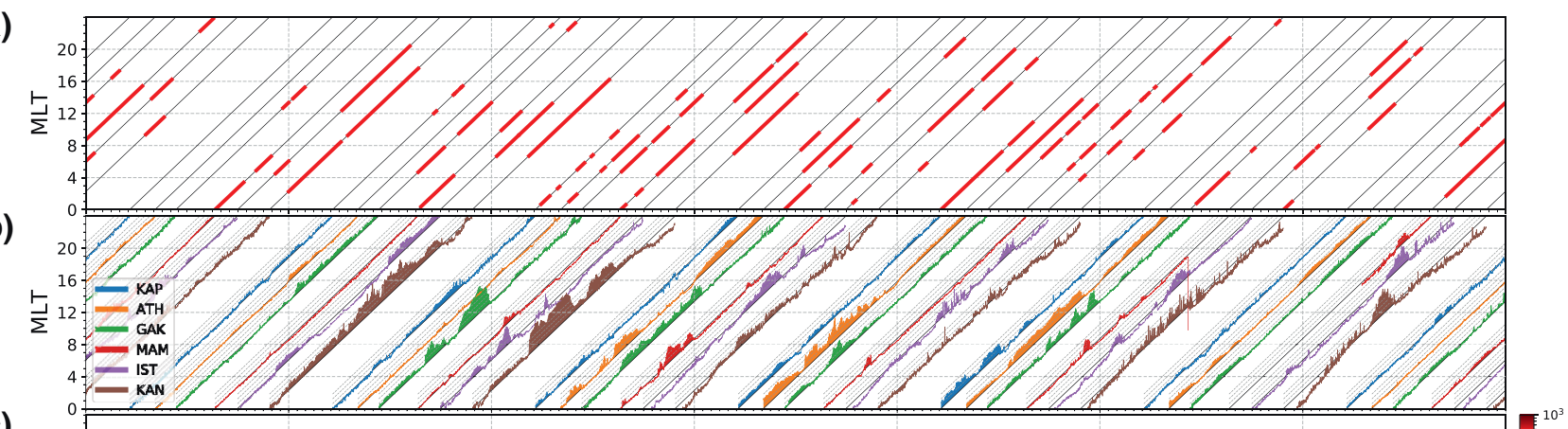

(c)

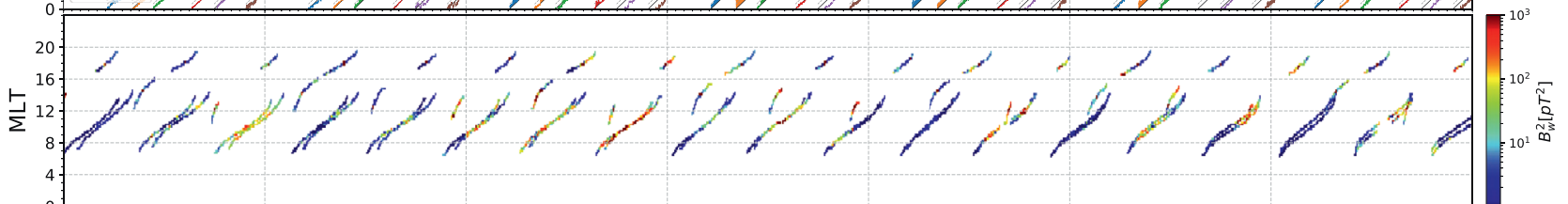

(d)
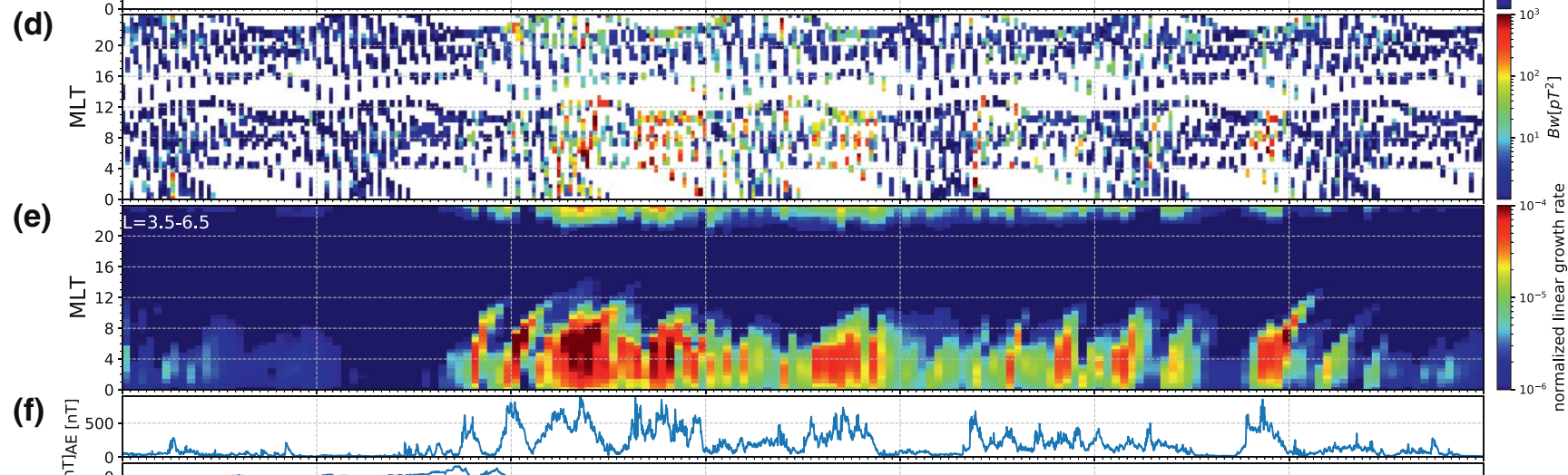

(g) ${ }_{2}=50$ (a)
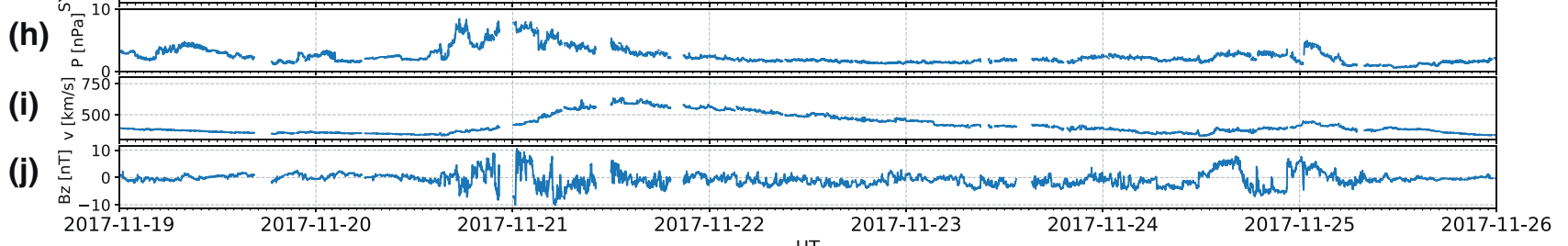

Figure 8. Spatiotemporal distribution of magnetospheric ELF/VLF waves from November 19, 2017 to November 26, 2017, including the storm starting from November 20, observed by (a) and (b) PWING, (c) ERG and RBSP satellites, and (d) POES/MetOp and estimated by (e) RAM-SCB simulation. Panels (f), (g), (h), (i) and (j) show the time variation of AE index, SYM-H index, solar wind dynamic pressure, solar wind speed, and IMF-Bz, respectively. AE, Auroral Electrojet; ELF/VLF, Extremely Low-Frequency/Very Low-Frequency; ERG, Exploration of energization and Radiation in Geospace.

(described in Section 2.4), respectively. These plots are created by averaging the global distributions of these data shown in Figure 6 for an $L$-value range from $L=3.5$ to $L=6.5$ calculated by Tsyganenko 04 model. The sixth, seventh, eighth, ninth, and tenth panels of Figures 7-9 are time variation of Auroral Electrojet (AE) and SYM-H indices, solar wind dynamic pressure, solar wind speed, and the interplanetary magnetic field (IMF) Bz, respectively.

\subsection{March 26-April 1, 2017 Event}

Figure 7 shows the spatiotemporal distribution of magnetospheric ELF/VLF waves during the storm of March 26-April 1, 2017. The magnetic storm with SYM-H reaching -70 nT started on March 27, 2017 at $\sim 00$ UT. According to the PWING data in Figures $7 \mathrm{a}$ and $7 \mathrm{~b}$, the waves present with an MLT extent of $\sim 6-12$ MLT from $\sim 04$ UT on March 27 in the main phase of the magnetic storm to 12 UT on March 29 in the 


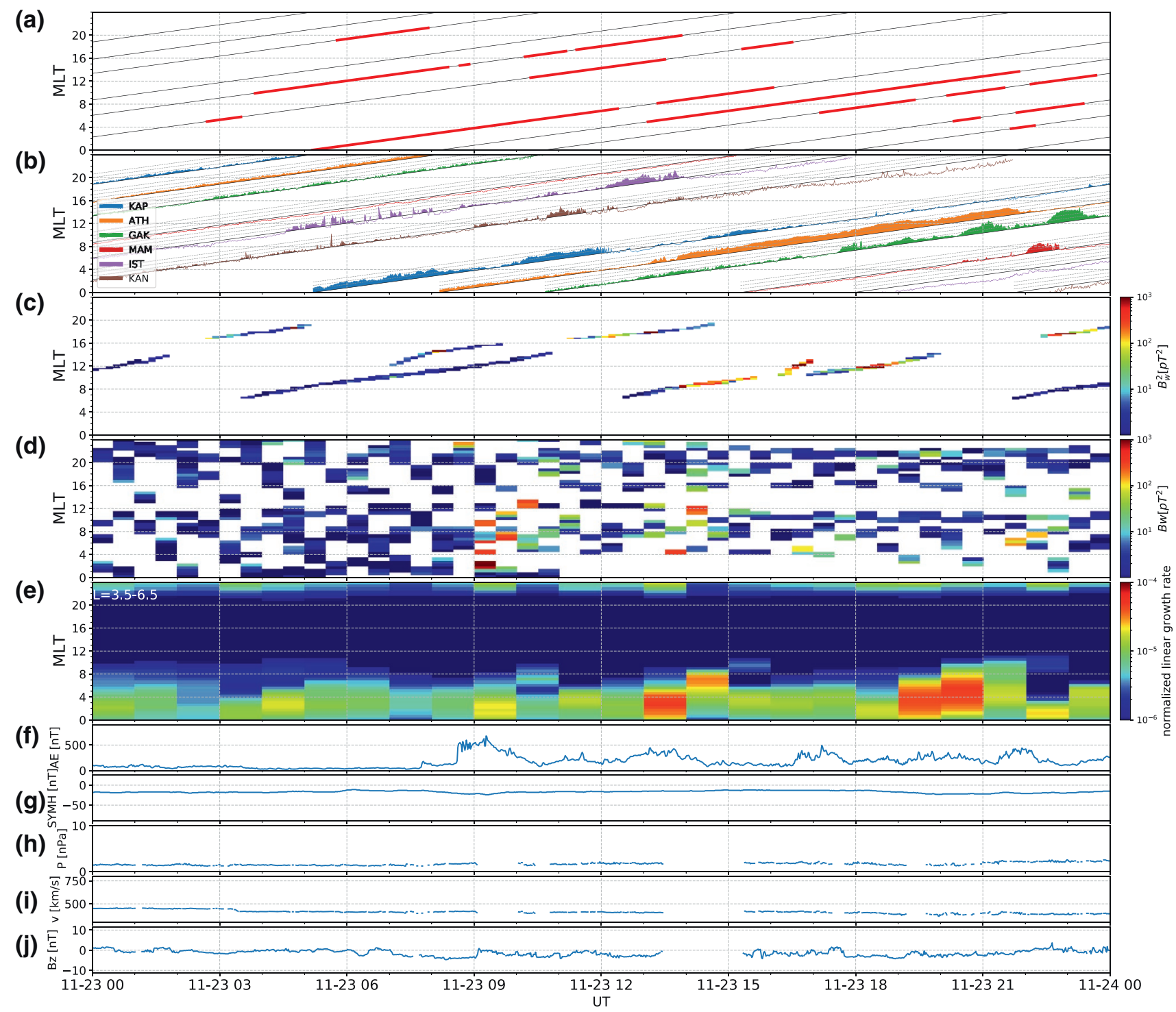

Figure 9. The 1-day spatiotemporal distribution of magnetospheric ELF/VLF waves on November 23 observed by (a) and (b) PWING, (c) ERG and RBSP satellites, and (d) POES/MetOp and estimated by (e) RAM-SCB simulation. Panels (f), (g), (h), (i), and (j) show the time variation of AE index, SYM-H index, solar wind dynamic pressure, solar wind speed and IMF-Bz, respectively. AE, Auroral Electrojet; ELF/VLF, Extremely Low-Frequency/Very Low-Frequency; ERG, Exploration of energization and Radiation in Geospace.

recovery phase. In the initial phase from $~ 18$ UT to $\sim 24$ UT on March 26, the waves were observed at the noon to the dusk sector from 12MLT to 16 MLT. In Figure $6 \mathrm{~b}$ there are enhancements of signal intensity at 20-24 MLT particularly at KAN. We consider them as enhancement of sferics, because they were not identified in the visual inspection in Figure 6a. The ERG satellite data in Figure 7c show the continuous appearance of the ELF/VLF waves with an MLT extent of $\sim 0-8$ MLT from $~ 04$ UT on March 27 in the main phase of the storm to $\sim 12$ UT on March 29 in the recovery phase. The Alfvenic fluctuation are observed associated with the high-speed solar wind during the recovery phase, which cause the continuous substorm activities and enhanced convections (Miyoshi \& Kataoka, 2005; Miyoshi et al., 2013). In the initial phase of the storm on March 26, the RBSP satellites also observed the waves in the dusk sector. The POES/MetOp observation shows the wave existence with an MLT extent of 20-12 MLT from 04 UT on March 27 in the main phase of magnetic storm to $\sim 16$ UT on March 28 in the recovery phase. In the initial phase on March 26, the POES/MetOp did not show any wave existence, contrast to the wave measurements of PWING, ERG, and RBSP. The spatiotemporal distribution of linear growth rate obtained from the RAM-SCB code in 
Figure 7e shows intermittent enhancements of wave growth rate with an extent of 00-12 MLT during the main and the recovery phase of the storm after March 27.

\subsection{November 19-26, 2017 Event}

Figure 8 shows the spatiotemporal distribution of magnetospheric ELF/VLF waves on November 19-26, 2017. This was a small storm with a minimum SYM-H index of -50 nT, which started at $\sim 08$ UT on November 20. In this period, the PWING ground stations were in full operation. Thus, we can observe spatiotemporal distribution in high local-time resolution. The spatiotemporal distribution obtained by the PWING ground stations in Figures $8 \mathrm{a}$ and $8 \mathrm{~b}$ shows continuous wave existence with an extent of $\sim 6-12$ MLT from $\sim 20$ UT on November 20 to $\sim 00$ UT on November 22. In the post-midnight sector (0-6 MLT), the waves were not observed. The ERG and RBSP satellite data in Figure $8 \mathrm{c}$ also show continuous wave existence with an extent of $\sim 8-12$ MLT from $\sim 00$ UT on November 21 to $\sim 00$ UT on November 22. The POES/MetOp data and RAM-SCB data in Figures 8d and 8e also show the continuous wave existence and enhancement of wave growth rate with an extent of $\sim 0-12$ MLT from $\sim 20$ UT on November 20 to $\sim 00$ UT on November 22. In the storm recovery phase starting from November 23, intermittent chorus waves were observed nearly at the same time by the PWING stations and in the POES/MetOp data in Figures $8 \mathrm{~b}$ and 8d. Large linear growth rates (Figure 8e) are found concurrently in the RAM-SCB simulation.

Figure 9 shows an enlarged view of the spatiotemporal distribution of magnetospheric ELF/VLF waves for the one day of November 23, during which the most-prominently observed feature was intermittent chorus waves. The chorus waves are observed on the ground in the order of KAP, KAN, and IST after the substorm that occurred at $\sim 08: 30$ UT with a maximum AE index reaching $~ 500 \mathrm{nT}$. POES/MetOp observation and RAM-SCB simulation also show the wave enhancement after the substorm. Further, the wave enhancement region expands to the morning sector in the PWING and POES/MetOp observations and RAM-SCB simulation. Similar chorus wave enhancements and dynamics can be seen after the substorms starting from $\sim 1630$ UT and $\sim 2130$ UT.

\section{Discussion}

\subsection{MLT Extent of Magnetospheric ELF/VLF Wave Caused by Substorm Injections}

We observed ELF/VLF waves associated with substorms in Figure 9 during the recovery phase of the November storm. These ELF/VLF waves associated with substorms were observed by ground and POES/MetOp observations and the RAM-SCB simulation. These waves often start from the night sector and expand to the dawn and dayside beyond 12 MLT. They have a drifting structure from nightside to the morning and dayside sectors, where its drifting speed seems to be 6-8 MLT/hour, as seen at 0240-0540 UT (Figure 9a), 1300-1530 UT (Figures 9a and 9b), and 2130-2230 UT (Figures 9a and 9b). This drift speed is in the same order to the drift speed of tens of keV electrons at $L \sim 6-8$. Thus, the observed azimuthal drift of waves is possibly caused by hot electrons injected from nightside and drifting eastward associated with magnetospheric substorms (e.g., Lam et al., 2010; Li et al., 2010; Meredith et al., 2001, 2012; Miyoshi et al., 2013). The discrepancy of $L$-values (PWING stations are at $L \sim 4$ ) may be due to inward expansion of the ELF/VLF waves to lower L-shells during their propagation from the magnetosphere to the ionosphere.

In the main to early recovery phase of the storm, substorms frequently occurred, and created continuous magnetospheric ELF/VLF waves for about a day with an extent from 0 MLT to 12 MLT. The waves observed around $\sim 20$ MLT may be caused by direct injection of electrons to the dusk sector by substorms.

\subsection{Lack of Waves in Ground-Based Observations in the Post-midnight Sector}

According to Figures $7 \mathrm{~b}$ and $8 \mathrm{~b}$, the ELF/VLF wave power observed on the ground tends to be enhanced after $\sim 4$ MLT, and there was little enhancement on the post-midnight sector at $\sim 00-04$ MLT. On the other hand, the ERG satellite observation in Figure $7 \mathrm{c}$ shows the wave existence before $\sim 4$ MLT. The POES/MetOp observation and the RAM-SCB simulation also imply wave existence before $\sim 4$ MLT. 
Li et al. (2009) investigated average ELF/VLF wave amplitude using the THEMIS satellite. They showed that the wave amplitude in the post-midnight sector attenuated more rapidly than that in the noon sector, as the wave propagated from the equatorial plane to middle latitudes. The night-side ELF/VLF waves tend to be confined in the equator plane, probably due to Landau damping during oblique propagation in the tailward-extended night-side field lines, or due to the absence of the plasma density duct structure. This can be the reason why the ELF/VLF waves were not observed in the PWING ground observation in the post-midnight sector. In addition, the enhanced ionization of the nightside ionosphere due to precipitating electrons possibly causes radio wave absorption in the post-midnight sector.

\subsection{Lack of Waves in POES/MetOp Observation and the RAM-SCB Simulation at Storm Initial Phase in the Dusk Sector}

In the initial phase of the March 2017 storm at 20-24 UT on March 26 in Figure 7, the ground station (ATH) and RBSP satellites observed the ELF/VLF waves in the dusk sector with a comparable magnitudes to that in the dawn sector during the storm. No waves were observed at KAP, though KAP was in the same local time as that of RBSP. This is probably because signal-to-noise ratio of KAP was worse than that at other stations. In this period, the dayside magnetopause was compressed by the increasing solar wind dynamic pressure, while the IMF Bz was still continuously positive. Thus, the ELF/VLF waves observed at ATH and RBSP were probably caused by the compression of the dayside magnetosphere, as reported by Shiokawa et al. (2014) and Zhou et al. (2015). The compression can cause enhancement of perpendicular electron temperature to generate ELF/VLF waves through betatron acceleration. The observed compression-driven ELF/VLF waves has a longitudinal extent of at least about $5 \mathrm{~h}$ in MLT. This longitudinal extent may express the size of the dayside compression region.

On the other hand, the POES/MetOp did not observe wave-associated precipitation in this dayside interval. This absence of POES/MetOp precipitation may be because of a lack of electrons scattered by the ELF/VLF waves before the start of the storm. Actually we identified the lack of trapped electrons in the POES/MetOp electron flux data in this dayside interval, probably because of a prolonged magnetically quiet condition ( $\sim 3$ days) before the storm.

At 12 UT on November 20, 2017 in Figure 8, which is before the start of the November storm, IST and KAN observed the ELF/VLF waves in the afternoon ( 12-20 MLT). Enhancements of solar wind dynamic pressure were not observed at this time. Thus magnetospheric compression is probably not the cause of these waves. At this time, the RAM-SCB simulation also did not show large linear growth rate and POES/ MetOp did not observe electron precipitation. No substorm activity is seen in the AE index. There must be some localized wave sources in the noon-dusk sector, though we could not identify them in the present data.

\section{Conclusions}

We have investigated the spatiotemporal development of magnetospheric ELF/VLF waves using PWING ground-based stations, ERG and RBSP satellites, POES/MetOp electron detector, and RAM-SCB simulations, with focusing on the March and November 2017 CIR-driven storms. The PWING six multi-point ground stations successfully observed local time development of magnetospheric ELF/VLF waves for the first time. The results of this study are summarized as follows:

1. The substorm-driven ELF/VLF waves were observed during the main and recovery phase of both storms. The waves were identified by the ground and POES/MetOp observations and the RAM-SCB simulations. They were observed from midnight to morning and dayside with eastward-drifting features. The drift speed identified from ground observation (about 6-8 MLT/hour) is comparable to that of tens keV electrons at $L \sim 6-8$

2. In the main to early recovery phase of the storms, we observe continuous ELF/VLF waves at local times from 0 MLT to 12 MLT. This wide extent seems to be caused by frequent occurrence of substorms

3. The magnetospheric compression-driven ELF/VLF waves were observed before the start of the March 2017 storm. They were observed only by ground and ERG and RBSP satellites in the noon sector with an MLT extent of at least $5 \mathrm{~h}$ 
4. The ground stations tend not to observe the ELF/VLF waves in the post-midnight sector, although other methods clearly show the wave existence. This is possibly due to Landau damping by oblique propagation along the extended night-side field lines, as suggested by Li et al. (2009), due to the absence of the plasma density duct structure in this local time sector, or due to enhanced auroral ionization of the ionosphere

These results show the global spatiotemporal development of magnetospheric ELF/VLF waves during storms for the first time. These results are important to create the ELF/VLF wave distribution model to predict the generation of relativistic electrons quantitatively.

\section{Acknowledgments}

The ELF/VLF data at ATH, GAK, KAP, IST, and MAM used in this paper are available from the ERG-Science Center operated by ISAS/JAXA and ISEE/ Nagoya University (https://ergsc.isee. nagoya-u.ac.jp/index.shtml.en, Miyoshi et al., 2018a). We express our sincere gratitude to Y. Katoh, H. Hamaguchi, Y. Yamamoto, and T. Adachi of ISEE for their continued technical support. The ELF/VLF loop antennas at ATH, GAK, KAP, IST, and MAM are operated with local support provided by Athabasca University, Geophysical Institute of University of Alaska Fairbanks, Virginia Polytechnic Institute and State University, the Institute of Solar-Terrestrial Physics (ISTP) of Siberian Branch of the Russian Academy of Sciences, and the Yu.G. Shafer Institute of Cosmophysical Research and Aeronomy (SHICRA) of Siberian Branch of the Russian Academy of Sciences, respectively. The ELF/ VLF wave data obtained at KAN are available at the Sodankyla Geophysical Observatory, University of Oulu, Finland (https://www.sgo.fi/pub_vlf/). The AE and SYM-H indices used in this paper were provided by the World Data Center-C2, Kyoto University and are available at http://wdc.kugi.kyoto-u. ac.jp. The authors thank the EMFISIS team for providing wave data from the VanAllen Probe spacecraft which was supported by JHU/APL contract no. 921647, under NASA Prime contract no. NAS5-01072 and JHU/APL contract no. 131802, and under NASA prime contract no. NNN06AA01C. The authors were also supported by the KAKENHI (Grant-in-Aid for Scientific Research; JP 15H05815 (KS, YM), JP 15H05747, JP 16H06286 (KS), 17H00728, 20H01959 (YM)) from the Japan Society for the Promotion of Science, by the Ministry of Science and Higher Education of the Russian Federation and the Siberian Branch of the Russian Academy of Sciences (project II.16.2.1, registration number AAAA-A17-117021450059-3), and were partially funded by the Russian Foundation for Basic Research (18-45-140037; D. B.), and by NASA contract NAS5-01072. This study was supported by JSPS Bilateral Open Partnership Joint Research Projects. MC is supported by Canada's NSERC.

\section{Data Availability Statement}

The PWING observation data are distributed by the Inter-University Upper atmosphere Global Observation Network (IUGONET) project of the Ministry of Education, Culture, Sports, Science and Technology of Japan. Science data of the ERG (Arase) satellite were obtained from the ERG Science Center. In the present analysis, the authors use Arase satellite data of PWE/OFA Level2 v02.01 (Kasahara et al., 2018b), ORB L2 v02 (Miyoshi et al., 2018b), and ORB_L3 (TS04) V02 (Miyoshi et al., 2018c). The ORB Level 3 v02 contains minor errors of $L^{*}$ (less than 0.05 for both events) compared with ORB Level 3 v01. The authors used the Van Allen Probes data of RBSP-A (-B)_WFR-SPECTRAL-MATRIX_EMFISIS-L2 and RBSP-A (-B)-RBSPICE_LEV-3_ESRHELT. All the data of Van Allen Probes, NOAA/METOP POES satellites and solar wind parameters used in this paper are taken from and publicly available at NASA CDAWeb (http://cdaweb.gsfc. nasa.gov/istp_public/ http://cdaweb.gsfc.nasa.gov/istp_public/). The RAM-SCB model is available from https://github.com/lanl/RAM-SCB.

\section{References}

Anderson, R. R., \& Maeda, K. (1977). VLF emissions associated with enhanced magnetospheric electrons. Journal of Geophysical Research, 82(1), 135-146. https://doi.org/10.1029/JA082i001p00135

Chen, Y., Reeves, G. D., Friedel, R. H. W., \& Cunningham, G. S. (2014). Global time-dependent chorus maps from low-Earth-orbit electron precipitation and Van Allen Probes data. Geophysical Research Letters, 41, 755-761. https://doi.org/10.1002/2013GL059181

Evans, D. S., \& Greer, M. S. (2004). Polar orbiting environmental satellite Space environment monitor-2 instrument descriptions and archive data documentation, NOAA tech. Mem. 1.4. Boulder, CO: Space Environ. Lab..

Hanzelka, M., \& Santolik, O. (2019). Effects of ducting on whistler mode chorus or exohiss in the outer radiation belt. Geophysical Research Letters, 46, 5735-5745. https://doi.org/10.1029/2019GL083115

Helliwell, R. A. (1965). In: Whistlers and related ionospheric phenomena. Stanford, CA: Stanford University Press, Vol.1.

Horne, R. B. (1989). Path-integrated growth of electrostatic waves: The generation of terrestrial myriametric radiation. Journal of Geophysical Research, 94(A7), 8895-8909.

Horne, R. B., \& Thorne, R. M. (2003). Relativistic electron acceleration and precipitation during resonant interactions with whistler-mode chorus. Geophysical Research Letters, 30, 1527. https://doi.org/10.1029/2003GL016973, 10

Jordanova, V. K., Thorne, R. M., Li, W., \& Miyoshi, Y. (2010). Excitation of whistler mode chorus from global ring current simulations. Journal of Geophysical Research, 115, A00F10. https://doi.org/10.1029/2009JA014810

Jordanova, V. K., Tu, W., Chen, Y., Morley, S. K., Panaitescu, A.-D., Reeves, G. D., \& Kletzing, C. A. (2016). RAM-SCB simulations of electron transport and plasma wave scattering during the October 2012 "double-dip" storm. Journal of Geophysical Research: Space Physics, 121, 8712-8727. https://doi.org/10.1002/2016JA022470

Jordanova, V. K., Welling, D. T., Zaharia, S. G., Chen, L., \& Thorne, R. M. (2012). Modeling ring current ion and electron dynamics and plasma instabilities during a high-speed stream driven storm. Journal of Geophysical Research, 117, A00L08. https://doi. org/10.1029/2011JA017433

Kasahara, Y., Kasaba, Y., Kojima, H., Yagitani, S., Ishisaka, K., Kumamoto, A., et al. (2018a). The Plasma Wave Experiment (PWE) on board the Arase (ERG) satellite. Earth Planets and Space, 70(1), 86. https://doi.org/10.1186/s40623-018-0842-4

Kasahara, Y., Kojima, H., Matsuda, S., Ozaki, M., Yagitani, S., Shoji, M., et al. (2018b). The PWE/OFA instrument Level-2 spectrum data of Exploration of energization and Radiation in Geospace (ERG) Arase satellite, V02.01. ERG Science Center, Institute for Space-Earth Environmental Research, Nagoya University. https://doi.org/10.34515/DATA.ERG-08000

Kennel, C. F., \& Petschek, H. E. (1966). Limit on stably trapped particle fluxes. Journal of Geophysical Research, 71, 1.

Kletzing, C. A., Kurth, W. S., Acuna, M., MacDowall, R. J., Torbert, R. B., Averkamp, T., et al. (2013). The electric and magnetic field instrument suite and integrated science (EMFISIS) on RBSP. Space Science Reviews, 179, 127-181. https://doi.org/10.1007/ s11214-013-9993-6

Lam, M. M., Horne, R. B., Meredith, N. P., Glauert, S. A., Moffat-Griffn, T., \& Green, J. C. (2010). Origin of energetic electron precipitation $>30 \mathrm{keV}$ into the atmosphere. Journal of Geophysical Research, 115, A00F08. https://doi.org/10.1029/2009JA014619

Li, W., Ni, B., Thorne, R. M., Bortnik, J., Green, J. C., Kletzing, C. A., et al. (2013). Constructing the global distribution of chorus wave intensity using measurements of electrons by the POES satellites and waves by the Van Allen Probes. Geophysical Research Letters, 40 , 4526-4532. https://doi.org/10.1002/grl.50920

Li, W., Thorne, R. M., Angelopoulos, V., Bortnik, J., Cully, C. M., Ni, B., et al. (2009). Global distribution of whistler-mode chorus waves observed on the THEMIS spacecraft. Geophysical Research Letters, 36, L09104. https://doi.org/10.1029/2009GL037595 
Li, W., Thorne, R. M., Nishimura, Y., Bortnik, J., Angelopoulos, V., McFadden, J. P., et al. (2010). THEMIS analysis of observed equatorial electron distributions responsible for the chorus excitation. Journal of Geophysical Research, 115, A00F11. https://doi. org/10.1029/2009JA014845

Manninen, J., Turunen, T., Kleimenova, N., Rycroft, M., Gromova, L., \& Sirviö, I. (2016). Unusually high frequency natural VLF radio emissions observed during daytime in Northern Finland. Environmental Research Letters, 11 https://doi.org/10.1088/1748-9326/11/12/124006

Martinez-Calderon, C., Shiokawa, K., Miyoshi, Y., Ozaki, M., Schofield, I., \& Connors, M. (2015). Statistical study of ELF/VLF emissions at subauroral latitudes in Athabasca, Canada. Journal of Geophysical Research - Space Physics, 120. https://doi.org/10.1029/2015JA021347

Mauk, B. H., Fox, N. J., Kanekal, S. G., Kessel, R. L., Sibeck, D. G., \& Ukhorskiy, A. (2013). Science objectives and rationale for the Radiation Belt Storm Probe mission. Space Science Reviews, 179, 3-27. https://doi.org/10.1007/s11214-012-9908-y

Meredith, N. P., Cain, M., Horne, R. B., Thorne, R. M., Summers, D., \& Anderson, R. R. (2003a). Evidence for chorus-driven electron acceleration to relativistic energies from a survey of geomagnetically disturbed periods. Journal of Geophysical Research, 108, 1248, A6. https://doi.org/10.1029/2002JA009764

Meredith, N. P., Horne, R. B., \& Anderson, R. R. (2001). Substorm dependence of chorus amplitudes: Implications for the acceleration of electrons to relativistic energies. Journal of Geophysical Research, 106(A7), 13165-13178. https://doi.org/10.1029/2000JA900156

Meredith, N. P., Horne, R. B., Sicard-Piet, A., Boscher, D., Yearby, K. H., Li, W., \& Thorne, R. M. (2012). Global model of lower band and upper band chorus from multiple satellite observations. Journal of Geophysical Research, 117, A10225. https://doi.org/10.1029/2012JA017978

Meredith, N. P., Horne, R. B., Thorne, R. M., \& Anderson, R. R. (2003b). Favored regions for chorus-driven electron acceleration to relativistic energies in the Earth's outer radiation belt. Geophysical Research Letters, 30, 1871. https://doi.org/10.1029/2003GL017698, 16

Miyoshi, Y., Hori, T., Shoji, M., Teramoto, M., Chang, T. F., Segawa, T., et al. (2018a). The ERG science center. Earth, Planets and Space, 70, 96. https://doi.org/10.1186/s40623-018-0867-8

Miyoshi, Y., \& Kataoka, R. (2005). Ring current ions and radiation belt electrons during geomagnetic storms driven by coronal mass ejections and corotating interaction regions. Geophysical Research Letters, 32, L21105. https://doi.org/10.1029/2005GL024590

Miyoshi, Y., Kataoka, R., \& Ebihara, Y. (2016). Flux Enhancement of Relativistic Electrons Associated with Substorms. In G. Balasis, I. A. Daglis, \& I. R. Mann (Eds.), Waves, particles, and storms in Geospace (pp. 333-353) Oxford Press.

Miyoshi, Y., Kataoka, R., Kasahara, Y., Kumamoto, A., Nagai, T., \& Thomsen, M. (2013). High-speed solar wind with southward interplanetary magnetic field causes relativistic electron flux enhancement of the outer radiation belt via enhanced condition of whistler waves. Geophysical Research Letters, 40. https://doi.org/10.1002/grl.50916

Miyoshi, Y., Morioka, A., Obara, T., Misawa, H., Nagai, T., \& Kasahara, Y. (2003). Rebuilding process of the outer radiation belt during the 3 November 1993 magnetic storm: NOAA and Exos-D observations. Journal of Geophysical Research, 108(A1), 1004. https://doi. org/10.1029/2001JA007542

Miyoshi, Y., Oyama, S., Saito, S., Kurita, S., Fujiwara, H., Kataoka, R., et al. (2015a). Energetic electron precipitation associated with pulsating aurora: EISCAT and Van Allen Probe observations. Journal of Geophysical Research: Space Physics, 120, 2754-2766. https://doi. org/10.1002/2014JA020690

Miyoshi, Y., Saito, S., Seki, K., Nishiyama, T., Kataoka, R., Asamura, K., et al. (2015b). Relation between fine structure of energy spectra for pulsating aurora electrons and frequency spectra of whistler mode chorus waves. Journal of Geophysical Research: Space Physics, 120, 7728-7736. https://doi.org/10.1002/2015JA021562

Miyoshi, Y., Shinohara, I., \& Jun, C.-W. (2018b). The Level-2 orbit data of Exploration of energization and Radiation in Geospace (ERG) Arase satellite, Version v03. ERG Science Center, Institute for Space-Earth Environmental Research, Nagoya University. https://doi. org/10.34515/DATA.ERG-12000

Miyoshi, Y., Shinohara, I., \& Jun, C.-W. (2018c). The Level-3 orbit data of Exploration of energization and Radiation in Geospace (ERG) Arase satellite, Version v02. ERG Science Center, Institute for Space-Earth Environmental Research, Nagoya University. https://doi. org/10.34515/DATA.ERG-12001

Omura, Y., Hikishima, M., Katoh, Y., Summers, D., \& Yagitani, S. (2009). Nonlinear mechanisms of lower-band and upper-band VLF chorus emissions in the magnetosphere. Journal of Geophysical Research, 114, A07217. https://doi.org/10.1029/2009JA014206

Omura, Y., \& Summers, D. (2004). Computer simulations of relativistic whistler-mode wave-particle interactions. Physics of Plasmas, 11 , 3530 .

Ozaki, M., Miyoshi, Y., Shiokawa, K., Hosokawa, K., Oyama, S. I., Kataoka, R., et al. (2019). Visualization of rapid electron precipitation via chorus element wave-particle interactions. Nature Communications, 10, 257. https://doi.org/10.1038/s41467-018-07996-Z

Ozaki, M., Shiokawa, K., Miyoshi, Y., Hosokawa, K., Oyama, S., Yagitani, S., et al. (2018a). Microscopic observations of pulsating aurora associated with chorus element structures: Coordinated Arase satellite-PWING observations. Geophysical Research Letters, 4512125 12134. https://doi.org/10.1029/2018GL079812

Ozaki, M., Yagitani, S., Kasahara, Y., Kojima, H., Kasaba, Y., Kumamoto, A., et al. (2018b). Magnetic Search Coil (MSC) of Plasma Wave Experiment (PWE) aboard the Arase (ERG) satellite. Earth Planets and Space, 70, 76. https://doi.org/10.1186/s40623-018-0837-1

Ozaki, M., Yagitani, S., Nagano, I., Hata, Y., Yamagishi, H., Sato, N., \& Kadokura, A. (2008). Localization of VLF ionospheric exit point by comparison of multipoint ground-based observation with full-wave analysis. Polar Science, 2(4), 237-249. https://doi.org/10.1016/j polar.2008.09.001

Santolik, O., Chum, J., Parrot, M., Gurnett, D. A., Pickett, J. S., \& Cornilleau-Wehrlin, N. (2006). Propagation of whistler mode chorus to low altitudes: Spacecraft observations of structured ELF hiss. Journal of Geophysical Research, 111, A10208. https://doi. org/10.1029/2005JA011462

Santolik, O., Gurnett, D. A., Pickett, J. S., Parrot, M., \& Cornilleau-Wehrlin, N. (2003). Spatio-temporal structure of storm-time chorus Journal of Geophysical Research, 108(A7), 1278. https://doi.org/10.1029/2002JA009791

Santolik, O., Macusova, E., Yearby, K. H., Cornilleau-Wehrlin, N., \& Alleyne, H. S. K. (2005). Radial variation of whistler-mode chorus: First results from the STAFF/DWP instrument on board the Double Star TC-1 spacecraft. Annals of Geophysics, $23,2937$.

Shiokawa, K., Katoh, Y., Hamaguchi, Y., Yamamoto, Y., Adachi, T., Ozaki, M., et al. (2017). Ground-based instruments of the PWING project to investigate dynamics of the inner magnetosphere at subauroral latitudes as a part of the ERG-ground coordinated observation network. Earth Planets and Space, 69(1), 160. https://doi.org/10.1186/s40623-017-0745-9

Shiokawa, K., Yokoyama, Y., Ieda, A., Miyoshi, Y., Nomura, R., Lee, S., et al. (2014). Ground-based ELF/VLF chorus observations at subauroral latitudes-VLF-CHAIN Campaign. Journal of Geophysical Research: Space Physics, 119. https://doi.org/10.1002/2014JA020161

Smith, R. L., \& Helliwell, R. A. (1960). Electron densities to 5 Earth radii deduced from nose whistlers. Journal of Geophysical Research, 65(9), 2583-2583. https://doi.org/10.1029/JZ065i009p02583

Streltsov, A. V., Lampe, M., Manheimer, W., Ganguli, G., \& Joyce, G. (2006). Whistler propagation in inhomogeneous plasma. Journal of Geophysical Research, 111, A03216. https://doi.org/10.1029/2005JA011357 
Summers, D., Ma, C., Meredith, N. P., Horne, R. B., Thorne, R. M., Heynderickx, D., \& Anderson, R. R. (2002). Model of the energization of outer-zone electrons by whistler-mode chorus during the October 9, 1990 geomagnetic storm. Geophysical Research Letters, 29(24), 2174. https://doi.org/10.1029/2002GL016039

Takeshita, Y., Shiokawa, K., Ozaki, M., Manninen, J., Oyama, S. -I., Connors, M., et al. (2019). Longitudinal extent of magnetospheric ELF/VLF waves using multipoint PWING ground stations at subauroral latitudes. Journal of Geophysical Research: Space Physics, 124, 9811-9892. https://doi.org/10.1029/2019JA026810

Thébault, E., Finlay, C. C., Beggan, C. D., Alken, P., Aubert, J., Barrois, O., et al. (2015). International Geomagnetic Reference Field: The 12th generation. Earth Planets and Space, 67, 79. https://doi.org/10.1186/s40623-015-0228-9

Tsurutani, B. T., \& Smith, E. J. (1974). Postmidnight chorus: A substorm phenomenon. Journal of Geophysical Research, $79(1), 118$.

Tsyganenko, N. A., \& Sitnov, M. I. (2005). Modeling the dynamics of the inner magnetosphere during strong geomagnetic storms. Journal of Geophysical Research, 110, A03208. https://doi.org/10.1029/2004JA010798

Yonezu, Y., Shiokawa, K., Connors, M., Ozaki, M., Manninen, J., Yamagishi, H., \& Okada, M. (2017). Simultaneous observations of magnetospheric ELF/VLF emissions in Canada, Finland, and Antarctica. Journal of Geophysical Research: Space Physics, 122, $6442-6454$. https://doi.org/10.1002/2017JA024211

Zhou, C., Li, W., Thorne, R. M., Bortnik, J., Ma, Q., An, X., et al. (2015). Excitation of dayside chorus waves due to magnetic field line compression in response to interplanetary shocks. Journal of Geophysical Research: Space Physics, 120, 8327-8338. https://doi. org/10.1002/2015JA021530 